\title{
V. Zäsur im März/April 1968: Die SPD zwingt den Kanzler noch stärker an die Seite seiner Fraktion
}

\section{Die Abkehr der SPD vom Mehrheitswahlrecht - Kiesinger spielt die Bedeutung der Frage herunter}

Ab 1968 begannen die innenpolitischen Probleme die Außenpolitik der Großen Koalition stärker zu bestimmen. Das Bündnis wurde im März 1968 durch die Entscheidung der SPD für den unbestimmten Aufschub einer Wahlrechtsänderung schwer belastet. Am 28. März trat Innenminister Lücke zurück - aus Protest gegen den Beschluß auf dem Nürnberger Parteitag. Lücke, der ehemalige CDU-Wohnungsbauminister, hatte viele Jahre lang eine große Koalition befürwortet. Schon im Jahre 1962 verhandelte er im Auftrag Adenauers mit Wehner über die Bildung einer Regierung von SPD und CDU/CSU. Ihn leiteten grundsätzliche politisch-philosophische Erwägungen. Er glaubte, daß die Beschränkung auf wenige Ṕarteien die Voraussetzung einer funktionierenden parlamentarischen Demokratie sei. Mit neunzehn Jahren hatte er den Untergang der Weimarer Republik erlebt, den er auf die Zersplitterung der demokratischen Kräfte zurückführte ${ }^{1}$. Diese Erfahrung war ein wesentlicher Grund, der ihn 1962, nach dem Bruch der Koalition, für die Bildung einer Großen Koalition plädieren ließ. Dabei spielten für Lücke der Anlaß sowie die Interessenlage der FDP bei der Beurteilung ihrer Aufkündigung keine Rolle. Wahrscheinlich, räumte er ein, müßten „solche Parteien“ sogar das eigene Wohl vor das Gemeinwohl, vor das Wohl des Staates stellen. Lücke hielt die Tatsache für bedrohlich, daß eine kleine Partei das gesamte System in eine Krise stürzen konnte ${ }^{2}$. Statt dessen wollte er auf Dauer ein Zweiparteiensystem etablieren. Nur über die Einführung des Mehrheitswahlrechts, meinte er, könne eine Aufsplitterung des Parteiensystems, wie er sie in Weimar erlebt hatte, vermieden werden. Als wesentliche Aufgabe der Großen Koalition betrachtete er daher die Einführung eines Mehrheitswahlrechts, das die Abhängigkeit der Regierung von Koalitionen mit kleinen Parteien aufhob. Wehner hatte dies 1962 als Vorbedingung für die Bildung eines schwarzroten

\footnotetext{
1 Vgl. Lücke, Weimar, S. 13; darin listete Lücke neben der Zersplitterung noch drei weitere Fehler des Weimarer Systems auf: Erstens habe es zu instabilen Regierungen geführt - zwischen 1919 und 1930 habe es 16 Reichsregierungen bei einer durchschnittlichen Regierungszeit von acht Monaten gegeben; zweitens habe sich der Typ der reinen wirtschaftlichen Interessenpartei in dieser Zeit mehr als verdoppelt (von 6 auf 14); drittens sei es zu einer Entfremdung zwischen Abgeordneten und Wählern gekommen, da nach Listen gewählt worden sei und nicht einzelne Personen zur Wahl gestanden hätten.

2 Vgl. Schwarz, Ära Adenauer, S. 272, sowie Mende, Wende, S. 65. Die FDP hatte sich durch die einseitig getroffenen Maßnahmen des Verteidigungsministers Strauß zum Rückzug aus der Koalition entschlossen. Strauß hatte Ende Oktober 1962 ohne Wissen des FDP-Justizministers Stammberger die Verhaftung des Spiegel-Redakteurs Ahlers in Spanien veranlaßt und seine Rolle in der Affäre im Bundestag zunächst verschleiert. Der Parteivorsitzende Mende erklärte daraufhin am 19.11.1962, die FDP sei zu einer Fortsetzung des Bündnisses bereit, aber im neuen Kabinett sei ihr eine weitere Zusammenarbeit mit Strauß nicht mehr zuzumuten.
} 
Bündnisses bereits akzeptiert, doch die SPD-Fraktion wollte dieser Absprache dann nicht folgen ${ }^{3}$.

Als die Bildung einer Großen Koalition im November 1966 erneut anstand, stellte die Änderung des Wahlmodus erneut eine Grundbedingung der Union dar. Wieder stimmte Wehner zu, aber diesmal auch seine Fraktion. In der Regierungserklärung betonte der Bundeskanzler, nach Auffassung der Regierung solle ein neues Wahlrecht in den siebziger Jahren klare Mehrheiten ermöglichen. Für die Bundestagswahl 1969 werde von der Regierung die Einführung eines Übergangswahlrechts beabsichtigt ${ }^{4}$. Doch zu einer Entscheidung in diesem Sinne sollte es nicht kommen. Als Kiesinger im November 1967 vorschlug, man solle schon 1969 nach dem Mehrheitswahlrecht wählen, und auch der CDU-Generalsekretär Heck erklärte, die außerordentlich schwierige Zusammenarbeit der Koalition mache eine Änderung der Wahlgesetzgebung bereits für die Wahl von 1969 notwendig, rief das beim Bündnispartner wieder ablehnende Reaktionen hervor ${ }^{5}$.

An sich waren die Sozialdemokraten ursprünglich nicht gegen ein Mehrheitswahlrecht eingenommen; sie hatten sich sogar zu Beginn der sechziger Jahre von seiner Einführung langfristig Vorteile versprochen. Sozialwissenschaftliche Institute hatten die Partei darin bestärkt, daß die junge, moderne SPD mehr und mehr zur Partei der Städte und damit der Zukunft werde, während die Union ihre Wählerschaften weiterhin aus dem Land rekrutiere. Daher würde sie langsam durch den Zug vieler Landbewohner in die Städte und die Auflösung der religiösen Bindungen an Stärke verlieren und in die Minderheit geraten $^{6}$. Dieser Trend schien sich 1960 zu bestätigen, als der damals 34-jährige Hans-Jochen Vogel bei einer Direktwahl mit 64 Prozent zum Oberbürgermeister Münchens gewählt wurde - eine spektakuläre Wahl, bedenkt man, daß es sich um die Hauptstadt des katholisch-konservativ geprägten Bayern handelte. Und drei Jahre später gelang es Brandt, bei der Landtagswahl in Berlin 62 Prozent der Stimmen, und der SPD, sämtliche (!) Direktmandate zu gewinnen. Doch Anfang 1968 sah die Lage anders aus. Die SPD war durch die Verluste bei den Landtagswahlen seit ihrem Eintritt in die Koalition nicht in der Stimmung, sich auf eine Änderung des Wahlmodus einzulassen7. Im Januar 1968 errechnete das Statistische Bundesamt, daß die Union 294 statt 245, die SPD aber nur 206 statt 202 Mandate im Bundestag errungen hätte, falls das für 1973 geplante Wahlrecht schon 1965 eingeführt worden wäre. Dieses Rechenexempel, aber auch ein Bericht vom der SPD nahestehenden Chef des Godesberger Instituts für angewandte Sozialforschung (Infas) Klaus Liepelt, der den Sozialdemokraten bei Einführung des Mehrheitswahlrechts keine Chancen einräumte, bremste ihre ohnehin geringe Entschlossenheit, schnell das

\footnotetext{
3 Vgl. Klotzbach, Weg zur Staatspartei, S. 527 f. Etwa die Hälfte der Fraktionsmitglieder sprach sich auch gegen eine Kanzlerschaft Adenauers und die Einführung des Mehrheitswahlrechts aus; siehe auch, wegen der Quellenlage, die persönlichen Aufzeichnungen Lückes, Gotto, Versuch einer Großen Koalition, und Roegele, Die Bemühungen.

4 Vgl. VdDB, 5. Wahlperiode, 80. Sitzung vom 13.12.1966, S. 3657.

5 Vgl. BPA, Kiesinger im WDR II, 18.11.1967, Anhang III, S. 2, sowie Welt am Sonntag, 19.11.1967. Zur allgemeinen Diskussion um das Wahlrecht siehe Hennis, Große Koalition ohne Ende?; Kaack, Mehrheitswahl; von der Vring, Reform oder Manipulation?; Bundesminister des Inneren (Hrsg.), Zur Neugestaltung des Bundestagswahlrechts.
}

6 Vgl. Baring, Machtwechsel, S. 109.

7 Vgl. Hildebrand, Erhard, S. 359. 
Mehrheitswahlrecht einzuführen ${ }^{8}$. Auf dem Nürnberger Parteitag vom 17. bis zum 21. März 1968 wurde der Beschluß vertagt. Die SPD verschob das Thema einfach auf einen außerordentlichen Parteitag.

Der Entschluß wurde beim Koalitionspartner nicht generell verurteilt. Strauß wertete ihn sogar als Entscheidung für die Fortsetzung der Großen Koalition über 1969 hinaus. Denn da die SPD noch immer an der Änderung des Wahlmodus interessiert zu sein schien, erweckte sie den Eindruck, erst in einer zweiten Legislaturperiode der Großen Koalition die endgültige Entscheidung hierüber treffen zu wollen.

Aber Strauß täuschte sich?. Bei den Sozialdemokraten spielte schon zu diesem Zeitpunkt die Frage nach der Zukunft der FDP eine wichtige Rolle. Zwischen beiden Parteien hatte in der Ost- und Deutschlandpolitik schon im November 1966 eine weitgehende Übereinstimmung geherrscht. Diese Gemeinsamkeit wurde durch die Beschlüsse des Hannoveraner Parteitags der FDP 1967 bekräftigt. Je stärker sich CDU/CSU und SPD über den richtigen Kurs der Ostpolitik stritten, desto wünschenswerter erschien manchem SPD-Abgeordneten eine sozialliberale Koalition nach den nächsten Bundestagswahlen 1969. In der Fraktionssitzung vom 5. März 1968 bestätigte Ahlers beispielsweise, daß bereits Gespräche mit der FDP über Koalitionsmöglichkeiten nach 1969 in einem Bonner Restaurant stattgefunden hatten. Das Treffen sei auf Initiative der FDP zustande gekommen. Näheres wurde den Abgeordneten nicht mitgeteilt. Lediglich der SPD-Fraktionsvorsitzende Schmidt kritisierte, künftige informative Kontakte zwischen sozialdemokratischen Amtspersonen und der FDP sollten „in den Ämtern und nicht in einer Gaststätte" stattfinden 10 .

Lücke nahm die Nürnberger Entscheidung der SPD verärgert und tief enttäuscht auf. Am 21. März unterrichtete er den Bundeskanzler, den Fraktionsvorsitzenden Barzel und den CDU-Generalsekretär Heck von seiner Absicht, unter den bestehenden Bedingungen sein Amt zur Verfügung zu stellen. Am nächsten Tag meldeten die Medien die Rücktrittsabsicht des Innenministers. Wehner, Lückes einstiger Verhandlungspartner, versuchte den Kollegen scheinbar von diesem Schritt zurückzuhalten. Unter dem 24. März schrieb er an ihn und verwies auf die negative Stimmung auf dem Parteitag, die befürchten ließ, das Vorhaben werde von der Partei vollständig und auf immer abgelehnt. Das für die Sache beste Ergebnis habe demnach in dem Beschluß bestanden, die Wahlrechtsfrage weiter der Diskussion und Prüfung zu überlassen. Aber Wehner ersparte Lücke am Ende den Vorwurf nicht, für die negative Entscheidung der SPD mitverantwortlich zu sein. Er wolle daran erinnern, daß er wiederholt darum gebeten habe, die Wahlrechtsfrage zeitig so zur Diskussion zu stellen, daß man nicht in Zeitdruck gerate. Als er das noch einmal Anfang Oktober 1967 gesagt habe, sei es schon sehr spät, aber immer noch nicht zu

${ }^{8}$ Vgl. Der Spiegel, 15.1.1968, S. 21. Hildebrand (Erhard, S. 360 f.) spricht von einer terminlich gezielten Veröffentlichung. Siehe zur Kritik am Bericht von Infas Lücke, Weimar, S. 61; Hennis (Große Koalition, S. 61 f.) bezweifelt die Prämissen Liepelts. Er weist auf die Tatsache, daß dieselben CDU-Wähler bei den Bundestagswahlen ihre Partei wählten, aber bei Landtagswahlen zu Hause blieben und somit zumindest die Bildung einer Regierung der Sozialdemokratie hinnähmen. Liepelt konzentriere sich bei seiner Untersuchung zu sehr auf sogenannte schichtenspezifische Merkmale, wie etwa die Konfession, anstatt den politischen Willen des Wählers zu berücksichtigen.

9 Vgl. Strauß, Erinnerungen, S. 406; dort korrigiert er diese Sicht und behauptet, mit dem Nürnberger Parteitag habe die SPD die Weichen gestellt in Richtung FDP.

10 AdsD, Protokolle interner Sitzungen der Führungsgremien, SPD-Fraktionssitzung vom 5.3.1968 im Berliner Reichstag, S. 2; laut Baring (Machtwechsel, S. 225) trafen sich Bahr und das FDP-Vorstandsmitglied Rubin nach dem Parteitag in Hannover, und man war sich in den wesentlichen Fragen der Deutschlandpolitik einig. 
spät gewesen. Dennoch sei auch Anfang Dezember noch nichts passiert, und es seien nochmals Wochen vergangen, bis man am 11. Januar 1968 das Gespräch habe führen können, in dem das Problem „Übergangswahlrecht“ erledigt und ein Verfahrensweg für die Behandlung der Vorlagen vorgezeichnet werden konnte. „Während dieser ganzen Zeit bin ich mir in zunehmendem Maße vorgekommen wie jemand, der zwar eine Stellung halten, aber dabei ganz auf sich allein angewiesen bleiben soll“, verteidigte sich Wehner ${ }^{11}$.

Obwohl Wehner mit dem Brief Lücke vor einem voreiligen Rücktritt bewahren wollte, war er es unabsichtlich dennoch, der den Minister schließlich darin bestärkte, sein Amt aufzugeben. In einem Gespräch zwischen Lücke und Wehner am 25. März verneinte der SPD-Politiker die Frage, ob er eine „reale“ Chance sehe, daß die Wahlrechtsfrage doch noch auf einem außerordentlichen Parteitag behandelt werden würde. Nach der SPDSatzung, erklärte Wehner, sei für die Einberufung eines außerordentlichen Parteitages der Antrag von mindestens neun Bezirksverbänden notwendig. Die Aussicht, ob und wann das geschehen könne, müsse er zurückhaltend beurteilen. Zu diesem Zeitpunkt, schreibt Lücke, habe für ihn kein Zweifel mehr bestanden, welche Schlußfolgerung er aus dem SPD-Entschluß habe ziehen müssen ${ }^{12}$.

Am nächsten Morgen, dem 26. März, erörterten zunächst die Unionsfraktion und der Kanzler die Beschlüsse der SPD. Lücke begründete seinen Entschluß, vom Amt zurückzutreten, mit der Feststellung, eine der wichtigsten Grundlagen der Großen Koalition sei nun entfallen. Für ihn sei die Wahlrechtsfrage „die Schicksalsfrage unserer parlamentarischen Demokratie“. Kiesinger war anderer Meinung. Seinem Minister hielt er in dieser Sitzung vor: „Wenn Sie so wenig Zutrauen in die demokratische Kraft des deutschen Volkes haben, wenn Sie glauben, nur durch eine Änderung, eine konstitutionelle Änderung die Zukunft dieses Volkes bestimmen zu können, dann stecken Sie lieber Ihren politischen Beruf besser heute als morgen auf. " 13 Kiesinger wollte unter keinen Umständen die Koalition wegen dieses Problems gefährden. Schon während der Verhandlungen um die Bildung der Großen Koalition im Jahre 1962 zeigte er sich zwar mit der Einführung des Mehrheitswahlrechts einverstanden, aber im Unterschied zu Lücke war er damals der Meinung, daß ein Regierungsbündnis der beiden großen Parteien auch dann geschmiedet werden sollte, falls das neue Wahlrecht sich nicht einführen ließe $e^{14}$.

11 AdKASt, Kiesinger I - 226, D/IV.6, Wehner an Lücke vom 24.3.1968, S. 2; Hildebrand (Erhard, S. 359) läßt das Argument nicht gelten. Trotz der Beanspruchung der Bundesregierung durch die Notstandsgesetzgebung sei man auf dem Gebiet Wahlrecht "recht zügig" vorangekommen. Er sei jedenfalls schon Ende des Jahres 1967 in der Lage gewesen, in die entscheidenden Besprechungen mit dem Koalitionspartner einzutreten. Hennis (Große Koalition, S. 72 ff.) bestreitet, daß der Brief die tatsächliche Stimmung des Parteitages wiedergibt. Der Parteivorstand habe die Sache hinausgezögert, meint der Politikwissenschaftler, der selbst Mitglied eines vom Innenminister 1967 zusammengestellten Beirats für Fragen der Wahlrechtsreform war. Wehner habe es sogar abgelehnt, die Einberufung eines Parteitags dem Vorstand zu überlassen. Im Anhang des kleinen Bändchens ist auch das unkorrigierte Protokoll der Diskussion auf dem Nürnberger Parteitag abgedruckt (S. 83-90). Auch Hildebrand (S. 362) schreibt, daß sich aus dem Parteitagsprotokoll die von Wehner beschriebene Situation nicht ergibt. Baring (Machtwechsel, S. 111) meint, Wehner habe mit dem Brief Lücke von dem Kern des Problems, der ablehnenden Haltung in der SPD gegenüber einer Änderung des Wahlmodus, ablenken wollen und ihm daher vorgeworfen, die Sache verschleppt zu haben.

12 Vgl. Lücke, Weimar, S. 73.

${ }^{13}$ Hildebrand, Erhard, S. 363 f.; das Zitat stammt aus dem Protokoll der CDU/CSU-Fraktionssitzung vom 26.3.1968.

14 Vgl. Lücke, Weimar, S. 39. 
Andererseits zeigte sich der Kanzler noch nicht bereit, den Minister, der inzwischen sein Rücktrittsgesuch eingereicht hatte, einfach ziehen zu lassen. Immerhin galt Lücke als eine Stütze der Großen Koalition. Am Nachmittag bat Kiesinger ihn noch einmal zu sich. Er eröffnete ihm, daß der soeben unter seinem Vorsitz zusammengetroffene Kreßbronner Kreis Möglichkeiten aufgezeigt habe, wie die Wahlrechtsfrage dennoch in der laufenden Legislaturperiode behandelt werden könnte. Dort hatte Brandt zunächst erklärt, auf dem Parteitag habe sich starker Widerstand gegen das reine Mehrheitswahlrecht geregt. Aber, so fügte er hinzu, auf der Basis sogenannter Viererwahlkreise ${ }^{15}$ sei eine Lösung möglich. Diese Frage sei allerdings noch nicht reif, mit ihr werde sich die Wahlrechtskommission der SPD befassen ${ }^{16}$.

Noch einmal zog Lücke nach dem Treffen mit Kiesinger sein Gesuch zurück. Aber er machte gleichzeitig deutlich, daß er nur dann weiter im Amt bleibe, falls die SPD ihm die Zusage für einen außerordentlichen Parteitag geben könne. Eben dies konnte und wollte keiner der SPD-Führer tun. Sowohl Wehner als auch Brandt hatten jeweils darauf hingewiesen, daß ein Parteitag theoretisch möglich, aber wenig wahrscheinlich sei. Das bestätigte Wehner Lücke erneut am 28. März 1968. Nach dieser letzten Vergewisserung trat der Bundesminister für Inneres von seinem Amt zurück.

Trotz der Tatsache, daß der Bundeskanzler die Verschiebung der Wahlrechtsänderung über 1969 hinaus durch die SPD nicht dramatisieren, sondern eher abwiegeln oder besser kalmieren - eines der Lieblingsworte Kiesingers - wollte, hinterließ die Entscheidung bei der Union einen anhaltenden Verdruß über den Koalitionspartner. Viele Christdemokraten dachten so wie der Bremer CDU-Abgeordnete Ernst Müller-Hermann, der Kiesinger erklärte, das Verhalten der SPD in der Wahlrechtsfrage sei „ein eindeutiger,

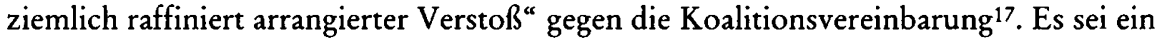
Fehler gewesen, daß die Zusage der SPD zur Einführung eines Mehrheitswahlrechts nicht schriftlich niedergelegt worden sei, meinte Heck noch zwanzig Jahre später. Die Union hätte darauf bestehen müssen, und die Wahlrechtsfrage habe wesentlich zum Ende der Großen Koalition beigetragen ${ }^{18}$.

\section{Unüberbrückbarkeit der Standpunkte zur Oder-Neiße-Linie - Kiesinger distanziert sich von Brandt}

Der Bundeskanzler sah sich einer schwierigen Situation ausgesetzt. Einerseits nahm die Kompromißbereitschaft der CDU/CSU-Abgeordneten mehr und mehr ab, mit Lücke

$15 \mathrm{Vgl}$. Lücke, Weimar, S. 169 f. und 178 ff., sowie Kaack, Zwischen Verhältniswahl und Mehrheitswahl, S. 80 f. Im Unterschied zum reinen Mehrheitswahlrecht, bei dem in einem Wahlkreis derjenige Abgeordnete gewählt wird, der die meisten Stimmen auf sich vereinigen kann, stellt bei dem Vorschlag von Viererwahlkreisen jede Partei vier Abgeordnete in einem Wahlkreis auf. Nach dem Verhältnissystem werden vier Mandate bestimmt. Es handelt sich daher also um eine Verhältniswahl in kleinen "Rechnungseinheiten“, den Vierer-Kreisen. Dieser Wahlmodus besteht bereits in Irland mit kleinen Abwandlungen seit 1923. Das Viererwahlsystem stärkt die größten Parteien, bietet aber auch kleineren und mittleren Parteien Möglichkeiten, besonders in regionalen Hochburgen Mandate zu erwerben.

16 Vgl. Hildebrand, Erhard, S. 362, Koalitionsgespräch vom 26.3.1968; im Protokoll heißt es wörtlich: „Ob es noch möglich sei, in der laufenden Legislaturperiode ein Wahlgesetz für 1973 zu verabschieden, sei zweifelhaft, aber das Thema sei keineswegs erledigt. Theoretisch sei es möglich, $\mathrm{da}$ noch in diesem Jahre ein außerordentlicher Parteitag zur Wahlrechtsreform stattfinde, wahrscheinlich sei das nicht."

17 AdKASt, Kiesinger I - 226, D/IV.6, Müller-Hermann an Kiesinger vom 22.3.1968, S. 1.

18 Vgl. Heck, Gespräch mit dem Verfasser, 4.10.1988. 
war nun eine wertvolle Stütze aus der Regierung ausgeschieden, und der Vorgang hatte das Ansehen der Großen Koalition in den Unionsreihen geschwächt. Andererseits verschärfte sich der Konflikt mit dem Außenminister. Der SPD-Vorsitzende schien sich im Frühjahr 1968 in der Ostpolitik nicht länger die Formeln des Kanzlers aufzwingen lassen zu wollen. Brandt übernahm in der SPD zugleich mehr und mehr das Kommando. Ehe der Parteivorsitzende auf dem Nürnberger Parteitag im März 1968 von der Notwendigkeit sprach, die Oder-Neiße-Grenze anzuerkennen oder zu respektieren, informierte er Kiesinger telefonisch über die geplante Äußerung. Wie zu erwarten, riet der Kanzler seinem Minister davon ab. Aber die Antwort Brandts war typisch für sein neues Selbstbewußtsein: Der Bundeskanzler sei zwar für die Richtlinien der Bundesregierung zuständig, nicht jedoch für die der sozialdemokratischen Partei ${ }^{19}$. Dennoch - ein letztes $\mathrm{Mal}$ - suchte der Kanzler nach einer Möglichkeit, die Äußerung des Außenministers auf dem Parteitag irgendwie in ein gemeinsames Konzept einzupassen. Brandt hatte am 18. März in Nürnberg seine Aussage zur Oder-Neiße-Linie mit dem Hinweis eingeleitet, das deutsche Volk wolle und brauche die Versöhnung mit den Polen - auch ohne zu wissen, wann es seine staatliche Einheit durch einen Friedensvertrag finden werde. „Daraus ergibt sich die Anerkennung bzw. Respektierung der Oder-Neiße-Linie bis zur friedensvertraglichen Regelung “, erklärte Brandt ${ }^{20}$.

Der Kanzler hatte zur Grenzfrage in der Regierungserklärung festgestellt, es werde zwar eine endgültige Lösung des Grenzproblems mit den Polen erst in einem allgemeinen Friedensvertrag gefunden werden, aber die Regierung könne schon jetzt versprechen, daß beide Seiten, Deutsche wie Polen, zu diesem Zeitpunkt eine Regelung finden würden. Gegenüber sowjetischen Journalisten hatte Kiesinger im März 1967 erläutert, wie er diese Erklärung interpretierte. Er sei bei dieser Frage auch in der Sache selbst weitergegangen, als es die deutsche Politik bis dahin getan hätte. Diese erweiterte Auffassung habe darin bestanden, zwar nach wie vor die endgültige Lösung des Grenzproblems einem allgemeinen Friedensvertrag vorzubehalten. Für diesen Fall sollte eine Lösung gefunden werden, die „von beiden Völkern angenommen werden könne“ 21 .

\section{Die Bundesrepublik und die Oder-Neiße-Linie - Von Adenauer bis zur Großen Koalition}

Damit wagte sich der Kanzler tatsächlich über das hinaus, was eine Bundesregierung bisher den Polen in der Frage der Oder-Neiße-Linie angeboten hatte. Schon in der unmittelbaren Nachkriegszeit hatten sich die westdeutschen Parteien - bis 1948 im übrigen auch die Kommunisten - gegen die Anerkennung dieser Ostgrenze gewandt. Der im Potsdamer Abkommen zwischen den Siegermächten vereinbarte Friedensvertragsvorbehalt ${ }^{22}$

19 Vgl. Brandt, Erinnerungen, S. 178.

20 Vorstand der SPD (Hrsg.), Parteitag März 1968 in Nürnberg, Rechenschaftsbericht des Parteivorsitzenden Brandt vom 18.3.1968, S. 111.

21 Oberndörfer (Hrsg.), Große Koalition, S. 40, Informationsgespräch mit sowjetischen Journalisten am 17.3.1967. Krülle (Die völkerrechtlichen Aspekte, S. 230) verweist allerdings darauf, daß Kiesingers Äußerung nicht im Widerspruch zu den bis dahin gegebenen Nichtanerkennungserklärungen gestanden habe, "da sie sich nicht auf den gegenwärtigen Rechtsstatus der Oder-NeißeGebiete“ bezogen hätte.

22 Vgl. Wagner, Die Entstehung der Oder-Neiße-Linie, sowie zur Haltung der Bundesrepublik: Bluhm, Die Oder-Neiße-Linie; Lehmann, Der Oder-Neiße-Konflikt. Zernack (Deutschlands Ostgrenze, S. 152) behauptet, daß sich nach 1945 das Bismarcksche Axiom, die Einheit Deutschlands sei nur durch den Fortbestand der Teilung Polens gewährleistet, umgekehrt habe. Im polnischen Verständnis habe nunmehr der Fortbestand Polens die Teilung Deutschlands verlangt. 
sowie die seit 1946 insbesondere von den Amerikanern auf den Außenministerkonferenzen geforderte Revision der polnischen Westgrenze (also die Rückgabe der deutschen Ostgebiete ohne Ostpreußen) ließen einen deutschen Anspruch auf diese Gebiete nicht aussichtslos erscheinen ${ }^{23}$. Schon während der ersten Bundestagsdebatte bekräftigten die beiden Führer der größten Parteien, Adenauer für die CDU/CSU und Schumacher für die SPD, ihre Ablehnung der Oder-Neiße-Linie als Grenzverlauf. Neun Monate später - kurz bevor die DDR mit Polen den Grenzvertrag von Görlitz schloß - legten alle Bundestagsparteien, bis auf die KPD, eine förmliche Rechtsverwahrung gegen das Görlitzer Abkommen ein. Wiederum ein Jahr später, im November 1951, verhandelte Adenauer mit den Hochkommissaren der westlichen Besatzungsmächte über einen deutschen Verteidigungsbeitrag, für den Bonn im Gegenzug die Souveränität erlangen sollte. Der Kanzler wollte die drei Westmächte vertraglich an die Wiedererlangung der Ostgebiete binden. Aber diese lehnten die Forderung ab. Adenauer mußte sich am 14. November 1951 die Frage des empörten englischen Hochkommissars, Sir Ivone Kirkpatrick, gefallen lassen, ob die Westmächte etwa verpflichtet seien, den Deutschen den polnischen Korridor wiederzugeben. Und der französische Diplomat, André François-Poncet, meinte, auf das französische Publikum werde diese Forderung des Kanzlers den Eindruck machen, daß die deutsche Beteiligung an der europäischen Integration nur das Ziel habe, mit bewaffneter Hand die deutschen Ostgebiete wiederzugewinnen ${ }^{24}$.

Doch Adenauer blieb hartnäckig: Was Ostpreußen betreffe, so seien die Westmächte in Potsdam vertragliche Verpflichtungen eingegangen, an denen die Deutschen nichts mehr ändern könnten ${ }^{25}$; das sei aber hinsichtlich Polens nicht der Fall. Er verlange daher von den Alliierten nicht mehr als die Auflösung der polnischen Verwaltung in den Gebieten östlich der Oder und Neiße26. Die Westmächte wollten den Deutschlandvertrag nicht an diesem Punkt scheitern lassen. Aber man vermied im Text eine endgültige Festlegung der Grenzen, bis zu der sich ein wiedervereinigtes Deutschland erstrecken

${ }^{23}$ Vgl. Körner, Die Frage der Ostgebiete, S. 648 f. Der Wandel in der amerikanischen Politik begann mit dem sogenannten Langen Telegramm des Gesandten der amerikanischen Botschaft in Moskau, Kennan, vom Frühjahr 1946; vgl. FRUS, 1946, Band 5, S. 555 f. Darin verlangte Kennan, die USA sollten sich um eine realistischere Einschätzung der Sowjetunion bemühen. In einem Memorandum vom 10.5.1946 empfahl er, die amerikanische Regierung sollte von den Sowjets die wirtschaftliche Vereinigung Deutschlands nicht nur bis zur Oder-Neiße-Linie, sondern bis zur deutschen Ostgrenze von 1937 - mit der Ausnahme von Ostpreußen - fordern. Das Telegramm findet sich gekürzt in deutscher Sprache in: Kennan, Memoiren eines Diplomaten, S. 552568; Außenminister Byrnes stellte in seiner Stuttgarter Rede vom 6.9.1946 erstmals die OderNeiße-Linie als deutsche Ostgrenze in Frage und dokumentierte damit öffentlich den Wandel in der amerikanischen Außenpolitik. Schließlich wurde auf der Moskauer Außenministerkonferenz vom Frühjahr 1947 die Revision der Oder-Neiße-Linie in die Verhandlungen eingebracht; vgl. Graml, Die deutsche Frage, S. 356, 369 und 372.

$24 \mathrm{Vgl}$. Baring, Kanzlerdemokratie, S. $136 \mathrm{f}$.

25 Vgl. Deuerlein (Hrsg.), Potsdam 1945, S. 361 ff. Über das Gebiet des nördlichen Ostpreußens heißt es im Potsdamer Abkommen, die Konferenz habe "grundsätzlich dem Vorschlag der Sowjetregierung hinsichtlich der endgültigen Übergabe der Stadt Königsberg und des anliegenden Gebietes an die Sowjetunion [...] zugestimmt".

26 Vgl. Baring (Kanzlerdemokratie, S. 138), der erklärt, trotz einer taktisch bestimmten Anpassung an die jeweiligen Gesprächspartner habe Adenauer daran geglaubt, daß die Westintegration der richtige Weg zur Wiedervereinigung sei. Er habe angenommen, die Rückgewinnung der Ostgebiete liege immerhin im Bereich des Möglichen. Körner (Ostgebiete, S. 649) behauptet, daß auch innenpolitische Faktoren Adenauer motivierten: Die Nichtanerkennung der OderNeiße-Grenze sei zum Instrument der Werbung der Parteien um Vertriebenenstimmen verwendet worden. 
solle27. Drei Jahre später, im September 1955, vereinbarte die Bundesrepublik diplomatische Beziehungen mit der Sowjetunion. Dabei akzeptierten die Sowjets den von den Deutschen vorgebrachten Rechtsvorbehalt: Die Aufnahme der Beziehungen bedeute keine Änderung des Rechtsstandpunktes der Bundesregierung in „bezug auf ihre Befugnisse zur Vertretung des deutschen Volkes in internationalen Angelegenheiten und in bezug auf die politischen Verhältnisse in denjenigen deutschen Gebieten, die sich gegenwärtig außerhalb der effektiven Hoheitsgewalt befinden“ 28 .

Bewegung kam in die deutsche Ostpolitik durch den Wunsch der neuen polnischen Führung gegen Ende des Jahres 1956, auch mit der Bundesrepublik Botschafter auszutauschen. Der erste Sekretär des ZK, Gomulka, reagierte damit auf eine Bemerkung, die der deutsche Außenminister im Mai 1956 während eines Aufenthaltes in London gemacht hatte. Von Brentano hatte damals - vermutlich wegen des bei den Bündnispartnern unterschwellig vorhandenen Unmuts über die Politik Bonns, auf der Rückgabe der Ostgebiete zu bestehen und die Oder-Neiße-Grenze daher nicht anzuerkennen ${ }^{29}$ - ausgeführt, er halte es für möglich, daß das deutsche Volk eines Tages vor die Frage gestellt werde, ob es auf die Ostgebiete zu verzichten bereit sei, um die 17 Millionen Deutsche in der Sowjetzone zu befreien. Es müsse dann entscheiden, ob es dies nicht tun wolle, „nur um einen etwas problematischen Anspruch auf die Ostgebiete aufrechtzuerhalten “ 30 . Die Aufstände in Posen und Warschau vom Sommer 1956 verstärkten noch das Bemühen der Deutschen um eine Annäherung. Polen wurde über Nacht zum Vorreiter und Hoffnungsträger eines liberalen, unabhängigen Landes im Ostblock. Die Bundesregierung dachte allerdings nicht an die Anerkennung der Grenze und schlug Gewaltverzichtsvereinbarungen vor $^{31}$. Über den Gesandten an der Bonner Botschaft in Washington, Albrecht von Kessel, liefen im Frühjahr 1957 die Verhandlungen mit den Polen. Ihm wurde der Vorschlag unterbreitet, diplomatische Beziehungen unter Ausklammerung der Grenzfrage aufzunehmen. Aus zwei Gründen kam es dann trotzdem nicht zur Aufnahme der Beziehungen. Einmal wollte Adenauer bei den bevorstehenden Bundestagswahlen den Block der Heimatvertriebenen und Entrechteten (BHE) unter die 5-Prozent-Klausel drücken, um damit der Union die absolute Mehrheit zu sichern ${ }^{32}$. Zweitens befürchtete das Auswärtige Amt eine Flut von Anerkennungen der DDR, sobald mit Polen der Grundsatz der Hallstein-Doktrin aufgegeben worden sei. Die Geburtsfehlerdoktrin entstand erst aufgrund dieses Dilemmas.

Die Polen traf an dieser Entwicklung auch ein gewisses Maß der Schuld. Am Tag der Bundestagswahl, dem 15. September 1957, platzte wie eine Bombe die Nachricht von

27 Vgl. Die Auswärtige Politik der Bundesrepublik Deutschland, S. 211; im Art. 7 I Satz 2 des Deutschlandvertrages heißt es: „Sie [die Unterzeichnerstaaten] sind weiterhin darüber einig, daß die endgültige Festlegung der Grenzen Deutschlands bis zu dieser [friedensvertraglichen] Regelung aufgeschoben werden muß.“

28 Meissner (Hrsg.), Moskau - Bonn, Band 1, S. 124.

29 Vgl. Schwarz (Ara Adenauer, 1957-1963, S. 30 f.), der etwa auf die Studie des Royal Institute for International Affairs (Wiskemann, Germany's Eastern Neighbours) verweist.

${ }^{30}$ Die Welt, 3.5.1956; vgl. Baring, Sehr verehrter Herr Bundeskanzler!, S. 192.

$31 \mathrm{Vgl}$. Die Auswärtige Politik, Außenminister Brentano auf einer Pressekonferenz in Berlin am 30.11.1956, S. 347.

32 Vgl. Körner, Ostgebiete, S. 650; Adenauer habe im katholischen Polen die Bastion der westlichen Zivilisation gegen die heidnische Welt des kommunistischen Ostens gesehen. Schwarz (Ära Adenauer, S. 32) erinnert daher daran, daß eine gewisse Rolle auch der Gedanke gespielt habe, eine demonstrative Annäherung zwischen Bonn und Warschau könne die Sowjets reizen und den inneren Reformprozeß des Landes gefährden. 
der schon oben erwähnten polnisch-jugoslawischen Erklärung. Darin hatten beide Delegationen die Oder-Neiße-Linie als endgültige polnische Westgrenze bekräftigt und die Jugoslawen die DDR als zweiten deutschen Staat anerkannt. Die Deutschen vermuteten zu recht, daß Gomulka Tito dazu angestiftet hatte, Ost-Berlin anzuerkennen. Damit war das Thema Polen für Bonn erledigt ${ }^{33}$.

Unerwartet geriet dann die deutsche Regierung in Bedrängnis, als Chruschtschow im November 1958 die zweite Berlin-Krise auslöste und eine Umwandlung der Stadt in eine „selbständige Einheit“ vorschlug. Zum Entsetzen Adenauers zeigte sich die Regierung der Vereinigten Staaten verhandlungsbereit. Das Weiße Haus ließ das Bundeskanzleramt nicht im unklaren über seine Einschätzung, daß die Aufnahme diplomatischer Beziehungen zu Polen und der Tschechoslowakei als festes Element eines zu schnürenden Verhandlungspaketes betrachtet wurde. Adenauer beugte sich dieser Haltung. Er schrieb in einer Denkschrift am 30. Januar 1959: „Verhandlungen müssen geführt werden. Bei diesen Verhandlungen könnte man auf Anregung der US in Erwägung ziehen, diplomatische Beziehungen der Bundesrepublik Deutschland zu Polen und der Tschechoslowakei herzustellen, falls die Berlin-Frage entsprechend gelöst wird. “34

Offensichtlich waren die Westmächte zu dem Schluß gekommen, daß sich die Bundesrepublik in gewissem Maße mit den Ergebnissen des Weltkrieges abfinden müsse. De Gaulle verkündete am 25. März 1959, er sehe die Oder-Neiße-Grenze als endgültige Ostgrenze eines wiedervereinigten Deutschland an ${ }^{35}$. Um eine Festlegung der Grenzen zu umgehen, verfocht Brentano wie schon 1956 den Vorschlag, Nichtangriffspakte mit den beiden östlichen Nachbarländern zu schließen. Für diese Politik erhielt er die Zustimmung Adenauers. Aber erneut gelang es nicht, die besprochene Linie durchzuhalten. Obwohl der Außenminister bereits die Verbündeten von dem Vorhaben der Bundesregierung unterrichtet hatte, Nichtangriffspakte für Warschau und Prag auf der Genfer Außenministerkonferenz anzubieten, scheiterte er im Juli 1959 am Widerspruch des Bonner Kabinetts ${ }^{36}$. Allerdings bewahrte dieser Rückzug einer angekündigten und von den Bündnispartnern für notwendig gehaltenen $\mathrm{Maßnahme} \mathrm{die} \mathrm{Bundesregierung} \mathrm{nicht} \mathrm{davor,} \mathrm{daß}$ die Westmächte nun ihrerseits die Initiative übernahmen. Auf der Gipfelkonferenz in Paris im Jahre 1960 wollte die amerikanische Administration, im Gegenzug für einen Modus vivendi in der Berlin-Frage, den Sowjets und vor allem den Polen eine Garantie der Oder-Neiße-Grenze anbieten. Erleichtert nahmen die Deutschen daher die Nachricht vom Scheitern der Gipfelkonferenz auf 37 .

33 Vgl. Baring, Sehr verehrter Herr Bundeskanzler, S. 194. Zwar hätte sich, nach Meinung von Schwarz (Arra Adenauer, S. 32), die Aufnahme durch die Geburtsfehler-Doktrin begründen lassen, aber Polen habe sein Spiel durch die Erklärung offensichtlich überreizt. Bender (Neue Ostpolitik, S. 47) weist darauf hin, daß die Polen auch weiterhin um die Bundesrepublik geworben hätten. Sie hätten 1957 und 1958220000 Deutschen die Übersiedlung erlaubt. Außerdem hatte im April 1958 der Sejm-Abgeordnete Stomma dem deutschen Außenminister gegenüber erklärt, daß die Grenzfrage noch immer offenbleiben könne.

34 Adenauer, Erinnerungen 1955-1959, S. 467.

$35 \mathrm{Vgl}$. Stercken (Hrsg.), Vive la France, S. 260.

36 Vgl. Baring, Sehr verehrter Herr Bundeskanzler!, Brentano an Adenauer vom 23.7.1959, S. 270 ff.; Adenauer hat seinen Außenminister in der Sitzung offensichtlich nicht unterstützt.

37 Adenauer kommentierte den Abbruch der Konferenz im kölnischen Dialekt: „Wir haben nochmals fies Jlück jehabt!“ (Eckardt, Ein unordentliches Leben, S. 614). Über die Motive, die Chruschtschow veranlaßten, den Gipfel platzen zu lassen, herrscht nach wie vor Unklarheit. Hillgruber (Europa in der Weltpolitik, S. 93) schreibt, der sowjetische Führer habe damit gezeigt, daß er nicht mehr bereit war, mit der ausscheidenden Eisenhower-Administration ein Arrangement zu treffen, sondern bereits auf die neue amerikanische Regierung setzte. Schwarz (Âra 
Allerdings verschlechterten sich die Bedingungen für die Bundesregierung in der Berlin-Krise. In der Kennedy-Administration tauchte in Arbeitspapieren und Diskussionen im Juli 1961 die bereits zuvor genannte Anerkennung der Oder-Neiße-Linie auf, und darüber hinaus dachten die Berater an eine de facto-Anerkennung der DDR; sogar ein neuer Berlinstatus als Konzessionsoption für die westliche Verhandlungslinie war im Gespräch ${ }^{38}$. Aber der Mauerbau in Berlin vom 13. August und schließlich das Abebben der Krise nach dem Kubazwischenfall ein Jahr später verhinderten, daß sich die beiden Supermächte am Verhandlungstisch darüber verständigten.

Hinsichtlich der Aufnahme diplomatischer Beziehungen mit Warschau wurde auch weiterhin von deutscher Seite aus sondiert. Es zeigte sich jedoch sehr schnell, daß Polen seit 1960 nicht länger bereit war, eine Grenzvorbehaltslösung zu akzeptieren oder auch nur eine Ersatzlösung anstelle diplomatischer Beziehungen zu erwägen ${ }^{39}$. Daran änderte sich auch nichts, als Außenminister Schröder ein neues ostpolitisches Konzept verfolgte, das auf den langsamen Aufbau von Beziehungen zu den Osteuropäern zielte. In der Logik dieses Vorhabens hätte auch die Hinnahme der Oder-Neiße-Linie gelegen. Aber so weit wagte sich der Außenminister nicht vor. Zwar sprach er vom „nationalpolitisch toten Raum der ehemaligen deutschen Gebiete jenseits der Oder und Neiße“40. Aber er beharrte auf dem Friedensvertragsvorbehalt. Mehr als den Austausch von Handelsverträgen mit den osteuropäischen Staaten schien auch der Bundestag damals nicht zuzulassen. Der sozialdemokratische Fraktionsvorsitzende Erler empfahl am 14. Januar 1965 auf einer Berliner Pressekonferenz, von deutscher Seite sollten Vorgespräche über das Grenzproblem mit den Polen geführt werden. Die innere Zustimmung der Deutschen zur Grenze solle die Basis für eine Freundschaft zum polnischen Volk sein. Aber bei den Parteien stieß der Vorschlag auf Kritik. Regierungssprecher von Hase kommentierte: Erlers Erklärung enthalte eine „Verzichtsmöglichkeit“. Wehner stellte für seine Partei klar, die einseitige Grenzziehung entlang der Oder-Neiße-Linie und die damit verbundene Annexion seien nicht rechtsverbindlich ${ }^{41}$.

Mit langsamem, aber stetig wachsendem Tempo hatte sich seit dem Mauerbau dagegen in der öffentlichen Meinung die These durchgesetzt, daß es für die Bundesrepublik von Vorteil wäre, die Grenzlinie anzuerkennen. Schriftsteller, Journalisten, Historiker wie Karl Jaspers, Marion Gräfin Dönhoff, Golo Mann, Sebastian Haffner, Klaus von Bismarck, Rüdiger Altmann, Theo Sommer fochten immer stärker für diese Politik. In einer Denkschrift setzte sich auch die Evangelische Kirche in Deutschland im Herbst 1965 für eine vorsichtige Wandlung in der Haltung zur Grenzfrage ein ${ }^{42}$.

Adenauer S. 107) nennt drei Gründe für den Abbruch: die Fehleinschätzung des amerikanischen Präsidenten, den Gesichtsverlust Chruschtschows gegenüber dem eigenen Politbüro und sein ungezügeltes Temperament. Siehe auch Lebow (Gespräch mit dem Verfasser, 9.7.1990), der in einer Reihe von Gesprächen mit Politikern und Verwandten Chruschtschows immer wieder auf die große Bedeutung stieß, die dieser dem persönlichen Verhältnis zu Eisenhower beimaß.

38 Vgl. Schwarz, Ara Adenauer, S. 135, und Körner, Ostgebiete, S. 653.

39 Vgl. Stehle (Nachbar Polen, S. 324 ff.) zu den Gesprächen, die der Industrielle Beitz in Polen 1960 und 1961 führte.

40 Körner, Ostgebiete, S. 653.

${ }^{41}$ AdG, 1965, S. 11639 f., sowie Körner, Ostgebiete, S. 654.

42 Vgl. Bender, Neue Ostpolitik, S. 118; Hildebrand, Erhard, S. 95; DzD, „Die Lage der Vertriebenen und das Verhältnis des deutschen Volkes zu seinen östlichen Nachbarländern“, Erklärung vom 15.10.1965, S. 896; siehe auch Henkys (Hrsg.), Deutschland und die östlichen Nachbarn. 


\section{Der Bruch zwischen Kiesinger und Brandt in der Ostpolitik wird deutlich}

Vor diesem Hintergrund deutete Kiesinger in seiner Regierungserklärung die Möglichkeit an, nach einem Friedensvertrag könnten die Polen mit der Anerkennung der OderNeiße-Linie durch die Regierung eines wiedervereinigten Deutschlands rechnen. Obwohl der Kanzler hier größere Flexibilität gezeigt hatte, hatte allerdings auch er einen Friedensvertragsvorbehalt ausgesprochen und keinerlei Garantien für die Haltung der deutschen Seite nach dem Friedensvertrag abgegeben. Kiesinger bot guten Willen an, mehr konnte und wollte er nicht tun.

Brandt ging einen radikaleren Weg. Er tastete sich vorsichtig an die "Anerkennung bzw. Respektierung" der Oder-Neiße-Linie heran ${ }^{43}$. Seine Erklärung stellte in zweifacher Hinsicht ein erheblich weitergehendes Zugeständnis an die Polen dar. Einmal zog der Außenminister die Anerkennung zeitlich vor den Friedensvertrag - was Kiesinger strikt ablehnte. Der Kanzler sprach am 14. März 1968 im Bundestag vom „politischen Angebot" seiner Regierungserklärung, auf das die Polen bisher nicht eingegangen seien. Es werde eine endgültige Klärung nur in einem Friedensvertrag geben, immerhin könne aber schon vorher „über verschiedene Lösungen“ gesprochen werden ${ }^{44}$. Zweitens bezeichnete der Außenminister die Oder-Neiße-Linie als Grenze. Das hatte Kiesinger bisher peinlich vermieden. Der Kanzler redete dagegen vom „Grenzproblem“.

Aber Kiesinger wäre sich untreu geworden, wenn er nicht zunächst auch in dieser Frage versucht hätte, die unüberbrückbar gewordenen Gegensätze zu überspielen oder sie zumindest herunterzuspielen. Gerade weil die Kritik an der SPD in den eigenen Reihen wuchs, wollte der CDU-Vorsitzende die Kluft zum SPD-Vorsitzenden nicht unüberwindbar werden lassen. Das tat der Kanzler allerdings nur unter einem klaren, verbalen Vorbehalt, den er eine Woche später in einer ersten Reaktion auf Brandts Erklärung machte. Kiesinger wirkte da im Ton erstaunlich milde, aber er ließ trotzdem keinen Zweifel an seinem unterschiedlichen Standpunkt zu Brandt aufkommen: „Was die Beschlüsse des Parteitages der SPD in Nürnberg und die Äußerungen des Parteivorsitzenden anlangt, so stimme ich der Feststellung zu, daß wir die Oder-Neiße-Linie bis zu einem Friedensvertrag mit einer gesamtdeutschen Regierung respektieren wollen ", erklärte er ${ }^{45}$. Diese Feststellung sei eine Konsequenz des Willens der Bundesregierung, diese Frage ausschließlich mit friedlichen Mitteln zu lösen. Dagegen halte er den Gebrauch des Wortes „Anerkennung" in diesem Zusammenhang für „unglücklich“, auch wenn es - wie der SPD-Parteivorsitzende gesagt habe - in der Sache nichts anderes bedeuten solle als Respektierung bis zum Friedensvertrag.

Das war ein schwacher Versuch Kiesingers, die beiden bestehenden Auffassungen miteinander in Einklang zu bringen. Was blieb der Bundesregierung schon anderes übrig, als die Oder-Neiße-Linie zu respektieren? Nur schien es Kiesinger langsam leid zu werden, Brandts Taten vor den Parteifreunden rechtfertigen zu müssen. Er machte aus seinem Mißtrauen gegenüber dem Minister jetzt auch öffentlich keinen Hehl mehr. So hatte Der Spiegel Anfang März 1968 den Satz kolportiert, Brandt träume wohl noch immer von einem sozialistischen Europa; der Außenminister mache sich Illusionen ${ }^{46}$. Kiesin-

${ }^{43}$ Vgl. Noack, Deutsche Außenpolitik, S. 115, und Richardson, Probleme und Aussichten, S. 615; Körner (Ostgebiete, S. 655) spricht von einer „Kursänderung“; Bender (Neue Ostpolitik, S. 149) meint, das Wort sei in Polen als Signal aufgefaßt worden.

${ }_{44} \mathrm{VdDB}, 5$. Wahlperiode, 160. Sitzung vom 4.3.1968, S. 8325.

${ }^{45} \mathrm{DzD}$, Kiesinger gegenüber DPA am 21.3.1968, S. 490.

46 Vgl. Der Spiegel, 11.3.1968, S. 20; Schmoeckel/Kaiser (Vergessene Regierung, S. 178) schreiben daher auch von einem „energischen Eingreifen“ Kiesingers gegen die Außerung Brandts. 
ger war sich bewußt, daß Brandt einen gefährlichen Kurs einschlug, den er selbst nicht wirklich verteidigen konnte und wollte. Daher betonte der Kanzler in seiner Stellungnahme Brandts „unglückliche Wortwahl“ - ein Understatement, das die Kritik Kiesingers etwas verschleiern sollte, aber daher auch nicht überzeugend wirkte ${ }^{47}$.

Allerdings verpflichtete der CDU-Vorsitzende seinen Generalsekretär, den Nürnberger Parteitag insgesamt positiv zu kommentieren. Im Deutschland-Union-Dienst verbreitete Heck demgemäß am gleichen Tage, Brandt, Wehner und Schmidt hätten auf dem Parteitag alles daran gesetzt, die Große Koalition und ihre Politik zu verteidigen. Sie hätten sogar eine Kraftprobe nicht gescheut, als sie nachträglich über den Eintritt in die Koalition abstimmen ließen. Mit $173 \mathrm{zu} 129$ Stimmen fiel die Zustimmung des Parteitags zum Eintritt in die Große Koalition dann doch überraschend deutlich aus. Selbst die Entscheidung über die Wahlrechtsfrage kommentierte Heck, der sonst heftig zu polemisieren wußte, mit sanften Worten. Er fügte sich der Linie, die Kiesinger ihm vorgab, obwohl er seine persönliche Enttäuschung nur schwer unterdrücken konnte. Als die SPD das Wahlrecht von der Tagesordnung absetzte, wollte auch er wie Lücke von seinem Amt als Familienminister zurückzutreten, bekannte er Jahre später. Doch Heck schreckte vor den Konsequenzen zurück. Denn dann hätte er auch seinen Posten bei der CDU aufgeben müssen ${ }^{48}$.

Deutlich kritisierte Heck hingegen Brandts Erklärung zum Grenzproblem mit Polen. Bei diesem Thema besaß er offenbar freie Hand. Auch die CDU wolle die Grenzen in Europa nicht mit Gewalt ändern und habe daher der Sowjetunion und den osteuropäischen Ländern einen Gewaltverzicht angeboten. „Hier nun, wie es in Nürnberg geschehen ist, das Wort ,anerkennen' hinzuzufügen, aber angeblich ,Anerkennung' nicht zu meinen, nützt uns, wie die polnische Reaktion zeigt, nichts; es kann nur Verwirrung stiften“, sagte Heck abschätzig49.

\section{Der Druck auf Kiesinger wächst}

Aber so einfach ließen sich die eigenen Parteimitglieder und vor allem die Vertriebenenverbände nicht beschwichtigen. Das deutete sich schon im Kommentar des stellvertretenden CDU-Fraktionsvorsitzenden Müller-Hermann an. Der ehrgeizige Unionspolitiker hatte im August 1967 dem Kanzler ein 28 Seiten umfassendes, persönliches Arbeitspapier vorgelegt ${ }^{50}$. Darin hatte der aus Königsberg stammende Abgeordnete geraten, in der Frage der ,jetzigen Ostgrenzen mit uns sprechen zu lassen“, unter der Voraussetzung, daß ein "größeres Europa“ zustande komme, in dem Grenzen lediglich eine Angelegenheit der Verwaltungstechnik sein würden, und innerhalb dessen Bewegungsund Niederlassungsfreiheit gewährleistet seien ${ }^{51}$. Jetzt, im Frühjahr 1968, nahm er die

47 Richardson (Probleme und Aussichten, S. 615) stellt fest, daß die Äußerung Brandts in der deutschen Öffentlichkeit - außer bei den Vertriebenen - auf bemerkenswert geringen Widerstand gestoßen sei.

${ }^{48}$ Vgl. Heck, Gespräch mit dem Verfasser, 4.10.1988. Der Generalsekretär, so jedenfalls Hecks Auffassung, sei so eng mit dem Vorsitzenden verbunden, daß er den Sessel räumen müsse, wenn er die Politik des Vorsitzenden nicht weiter mittragen wolle. Und das wollte Heck nicht: „Denn wer weiß, welche politischen Kräfte dann in der CDU hochgekommen wären?“

49 DzD, 1968, S. 493.

50 Vgl. Henkels, 99 Bonner Köpfe, S. 191. Der Politiker war schon Anfang der fünfziger Jahre aufgefallen, als er behauptete, daß man sich mit der Sowjetunion nicht ohne einen Preis werde arrangieren können.

${ }^{51}$ AdKASt, Kiesinger I - 226, A 006, Anlage zu Müller-Hermann an Kiesinger vom 30.8.1967, Gedanken über die Arbeit der CDU/CSU-Bundestagsfraktion in der zweiten Hälfte der Legislaturperiode, 29.8.1967, S. 12. 
Ostpolitik der SPD zum Anlaß, um die These Hecks von der Loyalität der in der Regierungsverantwortung stehenden SPD-Politiker anzuzweifeln. Im Brief an Kiesinger hieß es: „Ich kann [...] Ihre Meinung nicht teilen, daß die in der Regierungsverantwortung stehenden SPD-Politiker sich in Nürnberg, sehr mutig, politisch klug und auch loyal ${ }^{*}$ gegenüber den Regierungsvereinbarungen verhalten hätten. "Das Verhalten der SPD sei ein eindeutiger, „ziemlich raffiniert arrangierter Verstoß gegen die Koalitionsvereinbarungen". Die Formulierung, die SPD wolle die Oder-Neiße-Grenze respektieren und anerkennen, sei nicht nur "unglücklich“. Sie solle doch ganz bewußt mehr aussagen als „die Respektierung durch einen Friedensvertrag " 52.

Er, Müller-Hermann, könne sich denken, daß der Bundeskanzler in der derzeitigen Legislaturperiode „keine Alternative zur Großen Koalition“ sehe. Er teile diese Meinung, verbinde sie jedoch mit der Überzeugung, daß „auch die SPD keine Alternative“ besitze. Eine mögliche SPD/FDP-Koalition sei nicht einmal theoretisch erwägenswert. „Gerade diese Feststellung aber gibt uns in dieser Großen Koalition m. E. eine relativ starke Position. Wir sollten sie bei aller Loyalität gegenüber dem Koalitionspartner auch deutlich werden lassen, indem wir uns für die Erfüllung des Regierungsprogramms engagieren.“ Er sei davon überzeugt, daß seine Überlegungen auch in der Fraktion weitgehend geteilt würden, hieß es am Schluß.

Das war nur der Anfang einer heftigen Kritik an Brandts Vorstoß in der Oder-NeißeFrage. Sie betraf zugleich die Beurteilung des Vorgangs durch Kiesinger. Müller-Hermann legte in dem Schreiben vom 22. März dem Kanzler sogar nahe, nach der Wahl in Baden-Württemberg, wo man im Dezember 1966 ebenfalls eine Große Koalition gebildet hatte, einfach das Steuer herumzureißen und ein Bündnis mit der FDP anzustreben. Der Brief des stellvertretenden Fraktionsvorsitzenden ließ keinen anderen Schluß zu: Kiesinger mußte ihn als ernste Mahnung nehmen. Hinzu kam der Protest aus den Vertriebenenverbänden. Am 22. März 1968 erklärte der Ständige Rat der Ostdeutschen Landesvertretungen zum Nürnberger Parteitag am Ende eines Neun-Punkte-Papiers lapidar: Die überraschende Entscheidung des Parteitages scheine eine vertrauensvolle $\mathrm{Zu}$ sammenarbeit beenden zu sollen. „Wir vermögen bedauerliche Folgen in den kommenden Wahlen nicht abzuwenden. " 53 Ähnliche Erklärungen folgten vom Bund der Vertriebenen. Die Kritik wurde durch die offensichtliche Erfolglosigkeit der Brandtschen Äußerung in Osteuropa noch bestärkt. Denn die Polen fanden zwar, daß die deutschen Sozialdemokraten einen Schritt voran getan hatten, aber eben nicht mehr. Die Aufnahme diplomatischer Beziehungen könne allein damit nicht erreicht werden ${ }^{54}$.

Im Auswärtigen Amt hingegen betrachtete man schon früher die polnische Forderung, die Bundesregierung müsse die polnische Westgrenze anerkennen, als inkonsequent. Indem Warschau Bonn hierzu auffordere, habe es stillschweigend schon vorweggenommen, daß es nicht zwei deutsche, sondern nur einen deutschen Staat gäbe, machte man dort auf den Widerspruch in der Deutschlandpolitik Polens aufmerksam. Denn die Bundesrepublik besaß ja gar keine gemeinsame Grenze mit Polen. Also könne ein Anerkennungsersuchen nur von der Voraussetzung ausgehen, es existiere ein größeres

52 AdKASt, Kiesinger I - 226, A 006, Müller-Hermann an Kiesinger vom 22.3.1968, S. 1 f. (dort auch die folgenden Zitate); Müller-Hermann bezieht sich auf die Erklärung des Bundeskanzlers vom 21.3.1968, die weiter oben teilweise zitiert wurde. Allerdings hat er das Zitat falsch übernommen, es macht daher keinen Sinn. Er meint dagegen: „Respektierung bis zum Friedensvertrag“.

53 DzD, 1968, S. 498.

${ }^{54}$ Vgl. DzD, den Wojna: Trotz allem - ein Schritt voran, 1968, S. 506; Bender, Neue Ostpolitik, S. 157. 
Deutschland, das beide Staaten umfasse. Indem Polen von den Westdeutschen die Anerkennung forderte, nahm es die Wiedervereinigung vorweg 55 .

Wie dem sei, das Präsidium der CDU führte am 27. März 1968 mit dem Präsidium des Bundes der Vertriebenen ein versöhnliches Gespräch, in dem Kiesinger seine, inzwischen mit Außenminister Brandt abgesprochene Richtlinie zur polnischen Grenze einbrachte. Sie war sehr viel deutlicher formuliert als die früheren Äußerungen des Kanzlers und betonte den Friedensvertragsvorbehalt. Der SPD-Minister hatte offensichtlich den Rückzug angetreten und zugestimmt, daß als verbindendes Element der Koalitionspartner der Vorbehalt hervorgehoben werden sollte ${ }^{56}$. Vor dem Bundestag kommentierte der Kanzler an diesem Tag den ausgehandelten Kompromiß. Der entscheidende Satz lautete: „Die Grenzen eines wiedervereinigten Deutschlands können, wie dies auch der Außenminister in Nürnberg noch einmal unterstrichen hat, nur in einer frei vereinbarten Regelung mit einer gesamtdeutschen Regierung festgelegt werden. " ${ }^{57}$ Das waren wieder die Worte der Regierungserklärung. Von Respektierung oder gar Anerkennung war in der Verlautbarung nichts mehr zu lesen. Aber Kiesinger wußte, daß der Koalitionspartner noch einmal zurückgesteckt hatte, um die Koalition nicht zu gefährden, und möglicherweise schon bald erneut auf seinen neuen Kurs zurückkehren würde. Wenige Wochen später, im April 1968, erschien in der renommierten amerikanischen Zeitschrift Foreign Affairs ein Aufsatz von Brandt, in dem sich tatsächlich die als programmatisch zu verstehende Aussage fand: „Vielleicht können die Gewaltverzichtserklärungen, die wir angeboten haben, so formuliert und abgesichert werden, daß die derzeitigen polnischen Grenzen für die Zeit anerkannt werden, für die sich die Bundesrepublik festlegen kann, nämlich bis zu einer Friedensregelung. " 58 Das war der Beweis: Spätestens zu diesem Zeitpunkt ließ sich die unterschiedliche Politik beider Parteien selbst mit dem großen Talent des Kanzlers zum Ausgleich nicht mehr kaschieren. Vor diesem Hintergrund schlug die Nachricht von den heimlichen Kontakten zwischen Sozialdemokraten und Kommunisten Italiens in Bonn wie eine Bombe ein.

\section{Vertrauensbruch oder legitimer Alleingang? Die SPD bahnt sich den Weg nach Ost-Berlin über den Brenner}

Die Kontakte der SPD mit Führern der Kommunistischen Partei Italiens waren eher zufällig zustande gekommen. Schon im September 1967 ergriff die KPI die Initiative zu diesen Gesprächen. Der außenpolitische Redakteur des KPI-Zentralorgans L'Unità, Alberto Jacoviello, traf sich in Bonn mit einigen Journalisten, darunter dem damaligen Redakteur des Stern und späteren Berater Brandts, Leo Bauer.

Was wollte die KP Italiens? Sie versprach sich zweierlei: zum einen den Nachweis, daß man sich gegenüber den kommunistischen Parteien Osteuropas eine unabhängige Position geschaffen habe. Dadurch sollte die Attraktivität bei den Wählern erhöht werden; ihr Parteiführer Luigi Longo suchte Mitte der sechziger Jahre die Annäherung an die Sozialisten und den linken Flügel der Christlichen Demokraten. Zum anderen entsprach

\footnotetext{
55 Vgl. Diehl, Gespräch mit dem Verfasser, 29.11.1989.

56 Vgl. Bender (Neue Ostpolitik, S. 149), der darauf verweist, Brandt habe in Nürnberg nicht als Minister, sondern als Parteivorsitzender gesprochen.

57 VdDB, 5. Wahlperiode, 161. Sitzung vom 27.3.1968, S. 8462.

58 Brandt, German Policy toward the East, S. 484.
} 
die schrittweise Annäherung von Kommunisten und Sozialdemokraten den in den Karlsbader Beschlüssen vom April 1967 festgelegten Zielen. Die Konferenz hatte zwar harte Bedingungen für die Fortsetzung von Bonns Ostpolitik formuliert. In ihrem Abschlußkommuniqué räumte sie jedoch den kommunistischen Parteien größere Handlungsspielräume ein. Um die Friedensordnung Europas zu schaffen, wurde ihnen etwa "Agitation" erlaubt, aber auch gestattet, den Dialog mit Sozialisten, Sozialdemokraten, Gewerkschaftlern, selbst mit christlichen Kräften zu suchen, also mit Katholiken und Protestanten, in den kapitalistischen Staaten Europas ${ }^{59}$. Von einer europäischen Sicherheitskonferenz - ein Ziel, das in Karlsbad noch einmal bekräftigt wurde - erwarteten sich die italienischen Kommunisten eine Reihe positiver Veränderungen: eine allmähliche Verdrängung der Amerikaner aus Europa, die Auflösung der beiden Militärblöcke, eine Transzendenz der Wirtschaftsblöcke in Europa, also die Verschmelzung von EG und dem sowjetisch dominierten Rat für Gegenseitige Wirtschaftshilfe, sowie eine daraus gewonnene größere Handlungsfreiheit für alle west- und osteuropäischen Länder im allgemeinen und "ein linksregiertes Italien im besonderen"60.

Im Oktober 1967 reiste Bauer nach Italien, um zu sondieren und ein erstes Treffen zu vereinbaren. Bauer, 1912 als Kaufmannssohn in Skalat, nahe von Tarnopol in der Westukraine geboren, war in den Lagern der Nazis nur knapp dem Tode entronnen. Er be$s a ß$ in hohem Maße das Vertrauen von Brandt, zu dessen engem Beraterkreis er zählte. Mit Brandt und Wehner war abgesprochen, daß der Redakteur an Ort und Stelle entscheiden solle, ob sich der Kontakt mit der KPI überhaupt lohne. Er vereinbarte am 29. November in Rom ein Treffen. An diesem Tag traf sich eine dreiköpfige SPD-Delegation mit KPI-Vertretern. Neben Bauer waren vom konservativen Flügel der SPD Egon Franke sowie Fried Wesemann, damaliger SPD-Informationsdirektor, mit an den Tiber gereist. Wesemann protokollierte die Gespräche für die SPD. Ihnen gegenüber saßen das KPI-Vorstandsmitglied - der spätere Vater des Eurokommunismus - Enrico Berlinguer, und der Chef der ZK-Sektion für internationale Politik, Carlo Galluzzi. Hinzu gesellte sich der persönliche Sekretär des Parteichefs Longo, Sergio Segre, der als Korrespondent der L'Unità in Ost-Berlin gearbeitet hatte, mit einer Deutschen verheiratet war und daher ausgezeichnet Deutsch sprach. Longo, der Generalsekretär der KP, kannte Bauer aus der gemeinsamen Zeit im französischen Internierungslager zu Beginn des Zweiten Weltkrieges. Longo schätzte den Kameraden und hielt ihm die Freundschaft auch in der Nachkriegszeit. Selbst gegenüber Ulbricht leugnete er sein freundschaftliches Verhältnis zu dem Sozialdemokraten nicht. Bauer habe ihm im Lager „die Furunkel kuriert“, soll Longo dem Staatsratsvorsitzenden offenbar einmal sein gutes Verhältnis erklärt haben ${ }^{61}$.

Die Italiener konzentrierten sich bei dieser Unterredung zunächst auf die Wiederzulassung der Kommunistischen Partei Deutschlands, die 1956 in der Bundesrepublik als verfassungsfeindlich verboten worden war. Die KPI glaubte, in diesem Punkt der SED verpflichtet zu sein; außerdem passe das Verbot nicht in das Klima der neuen Ost-WestBeziehungen, meinten die Italiener. Sie zeigten sich daher nicht glücklich darüber, daß die SPD hier Vorbedingungen für eine Wiederzulassung nannte. Doch gaben sie sich zufrieden, als zugesichert wurde, es könne zwar die KPD aus verfassungsrechtlichen Gründen nicht wieder zugelassen, aber jederzeit eine neue Kommunistische Partei gegründet

59 Vgl. DzD, 1966-1967, Kommuniqué über die Konferenz der kommunistischen und Arbeiterparteien Europas in Karlsbad, S. 1053. Die SED sandte hierauf einen Brief an die Union, den diese allerdings brüsk zurückwies; vgl. BPA, Heck am 28.6.1967 im NDR, Anhang.

60 Timmermann, Im Vorfeld der neuen Ostpolitik, S. 390.

61 Brandt, Begegnungen, S. 290. 
werden. Auf ihre Frage, warum Ulbricht das denn nicht schon längst getan habe, mutmaßte Bauer ironisch, vielleicht aus Angst, eine neue KP könne sich so wie die KPI entwickeln. Die Bemerkung löste Heiterkeit bei den Italienern aus ${ }^{62}$.

Überhaupt schien die Verständigung zwischen den Vertretern beider Parteien sehr viel leichter zu sein, als die Deutschen nach der Abschottung durch die Karlsbader Beschlüsse befürchtet hatten. Die Repräsentanten der KPI beharrten zwar auf den Bedingungen der Konferenz, wonach die Bundesrepublik unter anderem alle bestehenden Grenzen sowie die Existenz des anderen deutschen Staates akzeptieren müsse. Aber sie verlangten keine völkerrechtliche Anerkennung der DDR, und es reichte ihnen aus, wenn die Deutschen die bestehenden Grenzen im Rahmen eines Gewaltverzichts hinnahmen. Franke soll dieser Sichtweise für die Sozialdemokraten zugestimmt haben. Falls die DDR in den Gewaltverzicht einbezogen und so ihre staatliche Existenz samt der Oder-Neiße-Grenze anerkannt werde, wäre dies „sehr begrüßenswert“ und könne zu „Hoffnungen auf eine europäische Sicherheitslösung Anlaß geben“", soll Franke nach einem Bericht Des Spiegel gesagt haben. Auf weitere Vorleistungen der Bundesrepublik, die in Karlsbad gefordert worden waren, bestanden die Italiener offenbar nicht. Vor dem ZK seiner Partei sprach sich Segre wenig später für die Unterstützung der „Brandt zugeschriebenen Absichten“ aus, lobte die neue Ostpolitik der SPD und deren mutige „Schritte auf dem Wege der Anerkennung der zwei Deutschlands"63.

Die Sozialdemokraten interessierten sich ihrerseits für die politischen Westeuropavorstellungen der Kommunisten. Brandt fand beispielsweise den Hinweis interessant, daß die KPI besonderen Wert darauf lege, im EG-Parlament durch ihre Abgeordneten vertreten zu sein ${ }^{64}$. Aber vor allem kam es der SPD auf mögliche positive Reaktionen der SED an. Würde sie, würden andere kommunistische Parteien überhaupt an einem gemeinsamen Konzept der Ostpolitik Interesse zeigen? Diese Frage beschäftigte auch die KPI. Segre und Galluzzi reisten nach dem Treffen nach Ost-Berlin und unterbreiteten dort den Inhalt der Gespräche. Innerhalb der SED gab es natürlich Vorbehalte. Die Italiener bekamen zu hören: „Das sind doch alles Kapitalisten, ihr werdet das schon noch merken. " 65 Doch die deutschen Kommunisten akzeptierten die Gespräche der italienischen Bruderpartei mit der SPD und schickten im Februar 1968 eine Delegation für zwölf Tage nach Rom, um die Interessenlage zu sondieren. Stolz berichteten die Italiener Brandt von dieser Entwicklung; der deutsche Außenminister verwandte sich seinerseits bei seinem italienischen Ministerkollegen, dem Christdemokraten Amintore Fanfani, für die Erteilung von Diplomatenvisa an die DDR-Delegation. Auf diesem Weg umging man die Schwierigkeiten, die es in jenen Jahren bei der Einreise von DDR-Bürgern in NatoLänder gab.

Worum es sich im einzelnen bei diesen Gesprächen drehte, ist nach wie vor unklar. Sicher ist, daß die Ost-Berliner von den Westdeutschen demonstrative Taten verlangten, die die Ernsthaftigkeit ihrer ostpolitischen Bemühungen bewiesen. Dabei ging es nicht nur um die Frage der Zulassung einer kommunistischen Partei in der Bundesrepublik. Auch über Einflußmöglichkeiten von Kommunisten in den Gewerkschaften sowie das künftige Verhältnis zwischen den beiden großen Arbeiterparteien wurde gesprochen ${ }^{66}$.

62 Vgl. Der Spiegel, 8.4.1968, S. 28.

${ }^{63}$ L'Unità, 16.2.1968; vgl. Timmermann, Im Vorfeld, S. 393.

64 Vgl. Brandt, Begegnungen, S. 291.

${ }^{65}$ Der Spiegel, 8.4.1968, S. 28.

66 Vgl. Kreutzer, Gespräch mit dem Verfasser, 22.8.1988; siehe auch Timmermann, Im Vorfeld, S. 394. 


\section{Die SED in Rom}

Paul Verner, Politbüromitglied und ZK-Sekretär, in den sechziger und siebziger Jahren zweiter Mann hinter Ulbricht und dann Erich Honecker, war der Spitzenrepräsentant der Sozialistischen Einheitspartei in Rom. Verners Entsendung muß als Zeichen für das starke Interesse Ost-Berlins an diesen Gesprächen gewertet werden. Er wurde begleitet von Werner Jarowinsky, Kandidat für das Politbüro und ZK-Sekretär, von Alois Bräutigam, dem ersten Sekretär der Erfurter Bezirksleitung, sowie den Mitgliedern des Zentralkomitees Alfred Kurella und Klaus Mehlitz, einem Italienspezialisten.

Was wollte die SED? Für ihre Delegation ging es zunächst darum, zu erfahren, ob sich überhaupt eine Basis für ein Gespräch zwischen SPD und SED finden ließ. 1966 war der Versuch gescheitert, einen Redneraustausch zwischen beiden Parteien zu organisieren. Ulbricht hatte damals aus Angst vor den Folgen und vermutlich auch auf Druck der Sowjets dieses Vorhaben aufgegeben ${ }^{67}$. Die Bereitschaft zum Dialog war nur vorhanden, wenn sich für die SED sichere Vorteile abzeichneten: Von der SPD erwartete das Politbüro, daß sich die Partei für die Anerkennung der DDR durch die Bundesrepublik einsetzte. Die Vertreter der SED übertrugen der KPI die Aufgabe, zu erkunden, inwieweit die SPD im Sinne der in Karlsbad formulierten Grundsätze Entgegenkommen signalisierte. Nach ihrer Rückkehr veröffentlichte die Delegation in Ost-Berlin ein Kommuniqué, das, verglichen mit früheren Dokumenten, an Schärfe verloren hatte. Einige der Vorbedingungen des Karlsbader Programms waren sogar beiseite gelassen worden, etwa die Anerkennung West-Berlins als besonderer politischer Einheit sowie die Nichtigkeit des Münchner Abkommens von Beginn an. Es fehlte auch die sonst übliche Kritik an der Einstellung der Bundesregierung zum Atomsperrvertrag. Im Mittelpunkt des Kommuniqués stand die Behauptung, „daß die Durchsetzung einer Politik der europäischen Sicherheit die Verständigung der kommunistischen, sozialistischen, sozialdemokratischen und christlichen Kräfte" erfordere. Diesen Satz hatten die italienischen Kommunisten der SED als Preis für die Vermittlung des Kontaktes zur SPD abgerungen. Die Italiener waren stolz auf diesen Erfolg. Das Bekenntnis zur Gemeinsamkeit schien ihnen eine vielversprechende Grundlage für weitere Gespräche zu sein ${ }^{68}$.

Im März 1968 kamen die Vertreter der KPI erneut mit denen der SPD zusammen. Diesmal traf man sich in München. Neben Bauer und Franke reiste jetzt auch der Ministerialdirektor im Auswärtigen Amt, Bahr, an - ein Hinweis darauf, daß die „Kontakte das Stadium bloßer Sondierungen überwunden hatten und in konkrete Regierungsinitiativen umgesetzt werden sollten" 69 . Über das Ergebnis der Gespräche und deren Inhalt bewahrte die SPD Stillschweigen. Aber die Italiener rechneten es sich ihren Vermittlungsdiensten an, daß Brandt am 18. März auf dem Nürnberger Parteitag der Sozialdemokraten erklärte, es gebe eine Notwendigkeit der „Anerkennung bzw. Respektierung der Oder-Neiße-Grenze“ - zumindest bis zu einer friedensvertraglichen Regelung. Auf der anderen Seite kritisierte die KPI, daß die SPD nach wie vor nicht für die Anerkennung der DDR eingetreten sei. An diesem Punkt seien die Meinungen anscheinend auseinandergegangen, urteilt Heinz Timmermann. Die Sozialdemokraten hätten behauptet, für

\footnotetext{
${ }^{67}$ Vgl. Bender (Neue Ostpolitik, S. 97), der behauptet, Moskaus Botschafter Abrassimow habe den Ausschlag gegeben. Er habe die anderen Ostbotschafter davon in Kenntnis gesetzt, die Sache werde nicht stattfinden.

68 Vgl. Timmermann, Im Vorfeld, S. 395.

${ }^{69}$ Ebenda.
} 
einen solchen Schritt sei die öffentliche Meinung in der Bundesrepublik noch nicht reif, was die Kommunisten allerdings nicht gelten lassen wollten 70 .

Enttäuschung bereitete es den Italienern auch, daß die SED an ihrer starren, mißtrauischen Einstellung gegenüber den Sozialdemokraten festhielt. Nach wie vor kritisierte etwa Nenes Deutschland die sozialdemokratischen Minister. So hieß es im Juni 1968, sie würden vom "westdeutschen Imperialismus" eingesetzt, um die "sozialistischen Länder gegeneinander auszuspielen" ${ }^{71}$. Immerhin zeigten sich wenigstens die Sozialdemokraten zufrieden. Als die Tatsache, daß Gespräche Anfang April 1968 stattgefunden hatten, an die Öffentlichkeit drang, erklärte ihr Parlamentarisch-Politischer Pressedienst, das Präsidium habe den Bericht über das Gespräch mit Vertretern der Kommunistischen Partei Italiens „mit Befriedigung“ zur Kenntnis genommen. Solche Gespräche lägen im Interesse der deutschen Politik. Man habe sich auf die Fortführung der Gespräche nach einer Denkpause geeinigt ${ }^{72}$.

\section{Die verbeimlichten Gesprächsthemen zwischen SPD und SED}

Für die Sozialdemokraten ging es darum, abzuschätzen, inwieweit eine Annäherung an die SED Möglichkeiten eröffnen würde. Es war notwendig geworden, Beziehungen zur kommunistischen Partei aufzubauen, „ohne daß man sich gegenseitig ins Gesicht schlug", wie Kreutzer später erläuterte ${ }^{73}$. Zuerst mußte aber einmal „taxiert" werden, welche Chancen für Übereinkommen überhaupt bestanden. Das war das Hauptziel der sozialdemokratischen Delegation ${ }^{74}$. Umgekehrt galt dies auch für die SED. Sie wollte Beweise dafür, daß die SPD ihre politischen Vorstellungen ernst meinte und nicht nur auf propagandistische Effekte bedacht war. Kreutzer, der enge Mitarbeiter Wehners, hat später im Gespräch mit dem Verfasser behauptet, daß die Sozialistische Einheitspartei die SPD durch ihre Mittelsmänner wissen ließ, ihr käme es vor allem auf zwei Forderungen an: Erstens solle die kommunistische Agitation in den westdeutschen Gewerkschaften wieder toleriert werden. Zweitens solle die ideologische Auseinandersetzung der SPD mit der Sozialistischen Einheitspartei zurückgestellt werden. Kreutzer beruft sich dabei auf Informationen, die ihm von Bauer gegeben worden sind. Den Aussagen Bauers folgend, ist es nicht zu Absprachen zwischen den Delegationen gekommen. Aus gutem Grund verheimlichte allerdings die SPD die beiden Diskussionsthemen, als Anfang April 1968 erstmals Hinweise über die KPI-Kontakte an die Öffentlichkeit gelangten. Falls die Union über den Gesprächsgegenstand informiert worden wäre, hätte dies mit Sicherheit zum Ende der Großen Koalition geführt.

70 Vgl. ebenda, S. 396: „Über die Kernfrage einer europäischen Entspannung - Lösung des Deutschlandproblems - gerieten die Verhandlungen ins Stocken. Die KPI mußte erkennen, daß die SPD dem von ihr vorgelegten Tempo in diesem Bereich nicht folgen konnte oder wollte."

71 Neues Deutschland, 12.6.1968.

72 Parlamentarisch-Politischer Pressedienst, 5.4.1968; Timmermann, Im Vorfeld, S. 396. Tatsächlich trafen sich Bauer und seine italienischen Kollegen weiterhin. Darüber hinaus fand nach der Bundestagswahl im Herbst 1969 eine öffentliche Diskussion in den beiden Parteiorganen Rinascita und Die Neue Gesellschaft - Bauer war 1968 Chefredakteur der SPD-Zeitschrift geworden über Fragen der Sicherheit in Europa statt, die schon im Mai/Juni-Heft von Die Neue Gesellschaft [3 (1969), S. 235 f.] angekündigt worden war.

${ }^{73}$ Kreutzer, Gespräch mit dem Verfasser, 22.8.1988.

$74 \mathrm{Vgl}$. Schmoeckel/Kaiser (Vergessene Regierung, S. 194), die dies zum Ansatzpunkt ihrer Kritik nehmen und der SPD Täuschung des Koalitionspartners vorwerfen. 


\section{Die Bedeutung der Kontakte}

Die Forderungen der SED-Delegation müssen von den Sozialdemokraten damals als sehr hoher Preis für eine Annäherung zwischen den Parteien eingeschätzt worden sein. Die Einheitspartei verlangte offenbar eine Umkehr der SPD-Entwicklung seit den fünfziger Jahren. Im Godesberger Programm von 1959 hatte die Sozialdemokratie dem Marxismus in aller Form abgeschworen. Sie hatte damals für ihre Partei beschlossen, sich vom Kommunismus noch deutlicher abzugrenzen, um den von ihr angestrebten, demokratischen Sozialismus glaubhaft zu machen. Das hatte Auswirkungen für die Ostkontakte, besonders diejenigen mit der SED, nicht aber für die ideologische Auseinandersetzung mit den osteuropäischen Kommunisten. In den „Richtlinien für Ostkontakte“ vom 30. Januar 1960 hatte die SPD erklärt, sie müsse dem Kommunismus einen dynamischen, selbstbewußten Offensivkurs der freiheitlichen Demokratie entgegensetzen. „Unsere Antwort auf die Herausforderung der kommunistischen Welt ist die Verwirklichung der sozialen Demokratie“, hieß es da. Diese müsse sich entfalten in einer „auf Frieden und Entspannung gerichteten, gleichwohl die prinzipielle Auseinandersetzung mit dem Kommunismus nicht scheuenden Außenpolitik, einer beharrlichen Wiedervereinigungspolitik, einer den Geist der Demokratie allseitig mobilisierenden Innenpolitik, kraftvollen wirtschafts-, bildungs-, sozial- und entwicklungspolitischen Initiativen und in einem sorgfältigen, objektiven Studium der Vorgänge im kommunistischen System "75.

Jetzt forderte die SED, daß die Sozialdemokratie die Auseinandersetzung um das ideologische Ziel zurückstellen solle. Das Politbüro fürchtete, besonders seit dem geplanten Redneraustausch 1966, die Konkurrenz der westdeutschen SPD im eigenen Staat ${ }^{76}$. Wenn die SPD an einer erfolgreichen Fortsetzung der deutschen Ostpolitik interessiert sei, so die Forderung, dann mußten diese sozialdemokratischen Angriffe gegen die Ideologie der SED verstummen.

Da die SPD die Gesprächsthemen geheimhielt und nicht offen diskutierte, gibt es kaum einen Hinweis darauf, ob ihre Führung tatsächlich dazu entschlossen war, die Möglichkeit kommunistischer Tätigkeit in der Bundesrepublik auszuloten. Es existiert in den Unterlagen dennoch ein Dokument, das immerhin Wehners Bemühungen belegt, zumindest eine der angesprochenen Forderungen auf ihre Durchsetzbarkeit beim Koalitionspartner hin zu testen. Der stellvertretende SPD-Vorsitzende hatte sich zu Beginn des Jahres 1968 an Kiesinger und Barzel mit der Bitte gewandt, man solle überprüfen, ob man den Kommunisten in der Bundesrepublik Diskussionsfreiheit zubilligen könne. Das betraf also offenbar die Forderung nach Zulassung einer Kommunistischen Partei, aber auch nach Freigabe kommunistischer Agitation innerhalb der Gewerkschaften. Barzel wies dies daraufhin in einem Brief vom 15. Februar 1968 zurück: „Hinsichtlich der Tätigkeit einer erneuerten kommunistischen Partei oder einzelner Kommunisten in der Bundesrepublik Deutschland sehe ich weder eine Möglichkeit noch einen Anlaß, die Lage zu verändern, wie sie durch das Urteil des Bundesverfassungsgerichts normiert ist“, schrieb er. „Sollte Herr Wehner wirklich den Kommunisten Diskussionsfreiheit hier einräumen wollen, so wäre dies wiederum eine einseitige Vorleistung von uns, ohne Gegenleistung

75 Klotzbach, Der Weg zur Staatspartei, Die Alternative unserer Zeit vom 30.1.1960, S. 458.

$76 \mathrm{Vgl}$. Kreutzer, Gespräch mit dem Verfasser, 22.8.1988. Kreutzer erklärt das geringe Vertrauen der SED-Führung in die eigene Überzeugungskraft auch damit, daß die Parteiführer ein Minderwertigkeitsgefühl befangen machte, weil sie zum großen Teil aus kleinbürgerlichen Verhältnissen stammten. "Daneben gab es das Trauma, 1933 versagt zu haben, deswegen sind sie 100 Prozent moskautreu.“ 
der anderen Seite." Er sei prinzipiell in allen Ost-West-Fragen der Meinung - ob es sich um Zeitungsaustausch oder Nichtverbreitungsvertrag handele -, daß die Frage der Gegenleistung gestellt werden sollte ${ }^{77}$.

Der Brief gibt über das Mißtrauen Barzels gegenüber dem Koalitionspartner Aufschluß. Ohne von den Gesprächen in Rom zu wissen, deren Existenz erst Anfang April durchsickerte, vermutete der Unionsfraktionsführer, Wehner schone bewußt die SED vor berechtigten und notwendigen Forderungen. Der Fraktionsführer ging sogar soweit, dem Minister für gesamtdeutsche Fragen Vernachlässigung seiner Amtspflichten vorzuwerfen. In demselben Brief kritisierte Barzel, ihn habe Wehners Vortrag vor dem Dienstagskreis der Koalitionsspitzen zu aktuellen gesamtdeutschen Fragen „entsetzt“. Er vermisse eine klare öffentliche Einlassung gegen den Verfassungsentwurf von Ulbricht ${ }^{78}$. Als wenige Wochen später die Kontakte zwischen SPD und KPI öffentlich bekannt wurden, fühlten sich Barzel und andere in der Unionsfraktion in ihrem Mißtrauen bestätigt.

Strauß hat behauptet, die SPD habe über die Kontakte zur KPI die spätere Brandtsche Ostpolitik nicht nur vorbereitet, sondern sogar abgesprochen. Die Ostpolitik habe ihren Ursprung in den römischen Geheimverhandlungen, meinte der CSU-Vorsitzende auch kurz vor seinem Tod in einer Besprechung von Schmidts Memoiren ${ }^{79}$. Brandt hat eben dies bestritten. Von den italienischen Kommunisten habe man lediglich Informationen über die Budapester Zusammenkunft des Warschauer Pakts erhalten, schreibt er in den Erinnerungen. Ausführlicher hat er sich dazu in den Begegnungen und Einsichten geäußert. Aber dort betont er, in erster Linie habe es sich nur um Informationen zur Haltung der KPI gehandelt, die die SPD interessiert habe ${ }^{80}$.

Alles in allem haben wohl beide recht. Der Ursprung der Ostpolitik liegt in dem Willen der Sozialdemokraten, mit dem Osten einen Ausgleich zu suchen. Die Große Koalition war nur eine Station auf diesem Weg. Die SPD suchte nach gemeinsamen Interessen mit der SED, durch die konstruktive Beziehungen geknüpft werden konnten. Darin lag der Sinn der Gespräche, wie auch Bauer später bestätigte. Der Vertrauensmann Wehners und Brandts erläuterte und rechtfertigte im April 1968 die Kontakte öffentlich mit dem Hinweis, die gemeinsam formulierte Politik der Regierungserklärung vom Dezember 1966 könne nur erfolgreich verwirklicht werden, wenn die Widerstände im kommunistischen Lager überwunden würden. Dazu müsse man mit den Kommunisten reden und verhandeln. Man dürfe der SED nicht das Exklusivrecht für die Darlegung und Interpretation der Politik der Großen Koalition gegenüber den anderen kommunistischen Parteien überlassen. Und wörtlich sagte er: „Die Begegnung von Rom zwischen italienischen Kommunisten und deutschen Sozialdemokraten dient ausschließlich dem Zweck der exakten Information und der klaren Interpretation der SPD-Politik und der Rolle der sozialdemokratischen Minister innerhalb der Bundesregierung. “81

Auch Strauß hat mit seiner Meinung nicht unrecht, wenn er zugleich von einem die Ostpolitik vorbereitenden Schritt spricht. Allerdings trifft die Behauptung nicht zu, daß zwischen SPD und SED schon einzelne Etappen des künftigen Vorgehens festgelegt worden seien. Die Sozialdemokraten verpflichteten sich zu nichts. Sie erhielten erst eine Vorstellung von dem, was sie die Zusammenarbeit mit der SED „kosten“ würde. Aber ihre

77 AdKASt, Kiesinger I - 226, D/IV.6, A 002, Barzel an Kiesinger vom 15.2.1968.

78 Siehe Weber (Geschichte der DDR, S. 386) zum Entwurf, der im Februar 1968 in der DDR bekanntgegeben worden war und am 6.4. zum Volksentscheid vorgelegt und angenommen wurde.

79 Vgl. Strauß, Das letzte Manuskript, in: Die Zeit, 7.10.1988.

80 Vgl. Brandt, Erinnerungen, S. 182, sowie Begegnungen, S. $291 \mathrm{f}$.

${ }^{81}$ Frankfurter Rundschau, 5.4.1968; vgl. Timmermann, Im Vorfeld, S. 392. 
Bereitschaft, sich auch hinter dem Rücken des Koalitionspartners über diese Probleme zu verständigen, trug dazu bei, daß sich die Hoffnungen der kommunistischen Parteien und Staaten Osteuropas von nun an auf die SPD konzentrierten.

\section{Kiesinger gibt die Verteidigung des Koalitionspartners auf}

Der Brief Barzels an Kiesinger vom 15. Februar 1968 zeigt, daß der Kanzler dem Fraktionsvorsitzenden ganz offensichtlich zustimmte, der Minister habe es versäumt, den neuen DDR-Verfassungsentwurf kritisch zu kommentieren. Die Unterstreichung des Hinweises auf die zu fordernden Gegenleistungen mit einem dicken Filzstift weist auf diesen Sachverhalt hin. Zudem hatte Kiesinger Barzels Bekenntnis, er sei „entsetzt“, noch durch ein dickes Ausrufezeichen am linken Rand des Briefes kommentiert und den Eindruck der Zustimmung dadurch verstärkt. Es war ein erstes, schwaches Anzeichen dafür, daß der Kanzler sich von der Deutschlandpolitik seines Ministers abzusetzen begann. Vermutlich war er es leid geworden, den Koalitionspartner andauernd wegen der Übertretung der Richtlinien in der Deutschland- und Ostpolitik vor den eigenen Parteileuten in Schutz zu nehmen.

Kaum waren fünf Monate vergangen seit dem Kreßbronner Treffen. Nicht nur hatten sich Brandt und Bahr fortwährend über die damals beschlossene Linie hinweggesetzt; auch Wehner hatte erneut seine eigenen deutschlandpolitischen Vorstellungen ohne vorherige Absprache mit dem Kanzler Journalisten dargelegt. Während sich Kiesinger zu einem Staatsbesuch in Italien aufhielt, meldeten am 2. Februar 1968 einige Zeitungen „brisante Thesen Wehners"82. Der Minister hatte der Pariser Monatszeitschrift Réalités ein Exklusivinterview gegeben und dort folgende Vorstellung einer künftigen Deutschlandpolitik in vorsichtigen, aber deutlichen Worten entwickelt: Zunächst sprach er von der Möglichkeit, daß zwei deutsche Staaten nebeneinander existieren könnten. Dann meinte er, ein Friedensvertrag müsse nicht notwendigerweise von einer Regierung eines wiedervereinigten Deutschland unterzeichnet werden, sondern könne auch von einer Regierung verhandelt werden, die von zwei Staaten für diese Aufgabe legitimiert worden sei. Noch einmal, wie ein Jahr zuvor, wies Wehner darauf hin, daß die Frage der Anerkennung dann gelöst werden könne, wenn in der DDR zumindest ein demokratisches Wahlrecht eingeführt worden sein sollte. Besonders heftig griff er die vier Großmächte, vor allem die Bündnispartner, an, die an der Festschreibung der Teilung Deutschlands schuld seien ${ }^{83}$.

Kiesinger hat sich zu diesen Gedanken nicht öffentlich geäußert. Aber sie widersprachen seinen Zielen. In seinen Reden, besonders deutlich in der am 11. März abgegebenen Regierungserklärung, wiederholte er die Bereitschaft zu Gesprächen zwischen den Regierungen, aber nur, wenn die DDR auf ihre Vorbedingung einer völkerrechtlichen Anerkennung durch Bonn verzichte. Lediglich in der Frage des Gewaltverzichts unterbreitete der Kanzler jetzt ein scheinbar neues Angebot, das allerdings gar nicht so neu war. Schon in der Regierungserklärung war davon die Rede, das „ungelöste Problem der deutschen Teilung“ in die Gewaltverzichtsverhandlungen mit einzubeziehen. Da aber Ulbricht sich weigerte, dieses Angebot überhaupt nur wahrzunehmen, erklärte Kiesinger im März 1968, die Bundesregierung erweitere den Kreis der vorgeschlagenen Themen „ausdrücklich“ um das Thema des Gewaltverzichts ${ }^{84}$.

82 Hamburger Abendblatt, 2.2.1968.

83 Vgl. Réalités, 2.2.1968.

${ }^{84}$ VdDB, 5. Wahlperiode, 158. Sitzung vom 11.3.1968, S. 8171. 
Wehners Drang, ohne Rücksprache seine Vorstellungen öffentlich darzulegen, blieb für Kiesinger ein fortgesetztes Ärgernis. Die SPD-Gespräche mit den italienischen Kommunisten, die ihm durch den Bundesnachrichtendienst aufgedeckt wurden, empfand er jedoch als schwerwiegende Verletzung der ungeschriebenen Koalitionsgesetze. Die einseitige Aufnahme des Dialogs mit der SED widersprach dem Geist der Koalition. Daß die SPD nicht unabhängig von der Union eine Verständigung mit der Sozialistischen Einheitspartei herbeiführen konnte, hatte Wehner bereits anerkannt, als er im Vorjahr anläßlich des SED-Parteitages den Koalitionspartner von dem geplanten Brief an Ulbricht unterrichtete. Vertrauliche Kontakte zur SED widersprachen aber dieser Haltung. Eine tiefe Kluft zwischen beiden Regierungsparteien brach hier jetzt auf, die auch das persönliche Verhältnis belastete.

\section{Informierte Wehner Kiesinger über die KPI-Kontakte?}

Die Aufdeckung der Kontakte führte zu einer Wende in Kiesingers Haltung gegenüber dem Koalitionspartner. Bisher war er darauf bedacht gewesen, seine Eigenständigkeit in den Konflikten mit Brandt und Wehner zu wahren: Um sich nicht einfach hinter den Reihen der eigenen Parteileute zu verstecken, nahm er die Eskapaden Wehners und die „Entgleisungen“ Brandts vor der eigenen Fraktion in Schutz. Das galt für Wehners Äußerungen zu Beginn des Jahres 1967 und für Brandts Bemerkungen zu den bestehenden Realitäten in Rumänien im Sommer desselben Jahres; schließlich gab es Kiesingers zitierten hilflosen Versuch, den Gegensatz zur Erklärung zu überdecken, die der Vorsitzende auf dem SPD-Parteitag zur Oder-Neiße-Linie Ende März 1968 abgegeben hatte. Aber die Suche nach Verständigung zwischen SPD und SED hinter seinem Rücken zwang den Kanzler dazu, erstmals in die Kritik seiner Fraktion gegen den Koalitionspartner einzustimmen.

Kiesinger ist das nicht leichtgefallen. Er befürchtete, beide Koalitionsparteien könnten sich so weit entfremden, daß dadurch die Basis seiner Regierung in Frage gestellt würde. Aber vermutlich gab es noch einen anderen Grund für sein anfängliches Zögern, die Eigenmächtigkeit des Koalitionspartners zu verurteilen. Denn möglicherweise trifft der Vorwurf von Strauß nicht die Wahrheit, Wehner habe ein „hinterhältiges Spiel“ getrieben und mit den italienischen Kommunisten gegen die eigene Regierung und gegen ihren Chef gearbeitet ${ }^{85}$. Ein Dokument vom Januar 1968 deutet darauf hin, daß Kiesinger von Wehner zumindest über die Ergebnisse des ersten Treffens beider Parteien im Rom vom November 1967 unterrichtet worden ist ${ }^{86}$. Unter dem 31. Januar 1968 sandte Wehner folgende handschriftliche Notiz an Kiesinger: „Hier ist der Bericht, über den ich gesprochen habe. Ich wäre Ihnen sehr dankbar, wenn Sie von den Namen, die er enthält, keinen Gebrauch machten. Leider fehlt ein kurzer spezieller Hinweis auf die besonderen Vorstellungen der dortigen Kommunisten über direktes Zusammenspielen mit ,der Kirche', den mir der Verfasser gegeben hat, der aber nicht zu dem Bericht gehörte. In der Eile konnte ich diese paar Zeilen nicht auftreiben." ${ }^{87}$

${ }^{85}$ Strauß, Erinnerungen, S. 404.

${ }^{86} \mathrm{Vgl}$. Schmoeckel/Kaiser, Vergessene Regierung, S. 190. Dort hat der ehemalige Bürochef Kiesingers in Bonn, Schmoeckel, bestätigt, daß Wehner Kiesinger auf „ausdrückliche Nachfrage“ eine Aufzeichnung der Gespräche Ende Januar 1968 übergeben hat. Sie habe aber kaum etwas über die von der SPD angeschnittenen Gesprächsthemen enthalten.

87 AdKASt, Kiesinger I - 226, D/IV.6, Wehner an Kiesinger vom 31.1.1968. 
Obwohl die zuerst erwähnte Anlage - außer der Ulbricht-Rede - nicht mehr bei den Akten zu finden ist, sprechen mehrere Gründe dafür, daß Kiesinger hier der sozialdemokratische Bericht über das erste Treffen mit der KPI übersandt wurde. Der Hinweis auf die „dortigen Kommunisten“ in Wehners Brief deutet darauf hin. Natürlich könnte es sich auch um andere Kommunisten im östlichen Teil Europas handeln. Erhellend ist hier aber das Stichwort „Kirche“, das vermutlich auf die damaligen Bestrebungen des Vatikans anspielt, sich mit den kommunistischen Parteien in Osteuropa zu verständigen ${ }^{88}$.

Ein weiterer Hinweis darauf, daß es sich um das Gesprächsprotokoll mit Vertretern der italienischen Kommunisten handelte, ist der Zusammenhang mit der DDR, wie ihn Wehner mit der Rede Ulbrichts zur neuen Verfassung herstellt. In der Rede vom Februar 1968 wollte der Minister das Augenmerk des Kanzlers auf Aussagen zur Einheit Deutschlands lenken. Ulbricht hatte da unter anderem ausgeführt, wenn die Kommunisten auch nichts mit der imperialistischen Gesellschaftsordnung Westdeutschlands verbinde, so verbinde sie mit den westdeutschen Arbeitern, den werktätigen Bauern und der fortschrittlichen Intelligenz die gemeinsame sozialistische, demokratische und friedliche Zukunft ${ }^{89}$. Dieser Satz erinnert an die zentrale Passage im Kommuniqué des römischen Treffens zwischen den deutschen und den italienischen Kommunisten, die die KPI der SED abgerungen hatte.

Und es existiert noch ein weiteres Dokument, das die These stützt, der Kanzler habe von den SPD/SED-Kontakten über die italienischen Mittelsmänner gewußt: der offizielle Text einer ersten Reaktion des Bundeskanzleramts vom 3. April 1968 auf die über die Medien verbreitete Nachricht, es hätten Gespräche zwischen Vertretern der SPD und der KPI stattgefunden. Vor der Fraktion erklärte der Kanzler später, er sei überrascht worden, erst der Bundesnachrichtendienst habe ihn informiert. Davon waren auch engere Mitarbeiter wie der persönliche Referent, Neusel, der Staatssekretär im Presseamt, Diehl, und der Staatssekretär im Kanzleramt, Carstens, überzeugt. Kiesinger sei über den BND in Pullach auf die Kontakte aufmerksam gemacht worden, erklärten sie noch Jahre später. Von den Informationen Wehners an Kiesinger ahnten sie nichts 90 .

Der Parlamentarische Geschäftsführer der CDU/CSU-Fraktion Rasner hatte aber recht, als er an den veröffentlichten Aussagen Kiesingers zweifelte. Am 5. April, zwei Tage nach dem Bekanntwerden der KPI-Kontakte, schickte er ein Schreiben ans Bundeskanzleramt. Einfach „zur Klärung “ übermittle er noch einmal den Wortlaut der DPA-Meldung vom 3. April, 17.58 Uhr: „Bonn, Bundeskanzler Kiesinger war über die Kontakte deutscher Sozialdemokraten mit Vertretern der Kommunistischen Partei Italiens unterrichtet. Mit dieser Erklärung nahm der Sprecher der Bundesregierung, Diehl, am Mittwoch in Bonn zu Äußerungen eines Sprechers des SPD-Vorstandes in Bonn vom Sonntag Stellung. Diehl wies darauf hin, daß diese Gespräche ausschließlich in die Verantwortung der SPD fielen." Rasner erklärte, später sei verlangt worden, in der Meldung 191 hinter das Wort „unterrichtet“ als Ergänzung das Wort „worden“ einzufügen. Von einer „nachträglichen “ Unterrichtung sei in keiner dieser DPA-Meldungen die Rede. „Sie werden, sehr verehrter Herr Bundeskanzler, mit mir sicher darin übereinstimmen, daß die

88 Vgl. Stehle, Die Ostpolitik des Vatikans, S. 334 ff., und ders., Neue Aspekte und Methoden vatikanischer Ostpolitik; Papst Johannes XXIII. hatte seit 1962 den Versuch unternommen, mit den kommunistischen Parteien in Osteuropa ins Gespräch und zu Verhandlungen zu kommen; vgl. Barzel (Gespräch mit dem Verfasser, 10.6.1988), der diese Sicht bestätigt.

89 Vgl. AdKASt, Kiesinger I - 226, D/IV.6, Anlage zu Wehner an Kiesinger vom 31.1.1968.

90 Vgl. Carstens, Diehl, Neusel, Gespräche mit dem Verfasser, 29.11.1989, 29.11.1989, 30.11.1989. 
$D P A$-Meldung keine andere Auslegung zuläßt, als die, die wir hier in der Fraktion ihr gegeben hatten." 91

Vielleicht hatte sich Rasner nicht getäuscht. Möglicherweise wollte Kiesinger zunächst gar nicht verdecken, daß man ihn über die Gespräche informiert hatte. Aber vermutlich hatte der Kanzler die Sprengkraft dieser Nachricht unterschätzt. Als er dann die aufgeregten Reaktionen seiner Parteifreunde erlebte, hatte er es für besser gehalten, einfach zu erklären, daß er von der Sache erst nachträglich unterrichtet worden sei. Mitte April 1968 bestätigte dann Longo, daß es zwischen ihm und Kiesinger, anläßlich der Italienreise des Bundeskanzlers im Februar 1968, zu einem Meinungsaustausch gekommen sei92. Longo berichtete, er habe mit dem deutschen Kanzler in wenigen Minuten viele Themen angesprochen: das Verbot der kommunistischen Partei in Deutschland, die Probleme der europäischen Sicherheit, die Grenzfrage, die Anerkennung der DDR. Es sei ein schneller Gedankenaustausch gewesen. Auch dies deutete darauf hin, daß der Kanzler eine Vorstellung von den Gesprächen gehabt haben mußte. Longo erklärte, er habe den Eindruck gewonnen, daß Bundeskanzler Kiesinger die Kontakte zwischen den italienischen Kommunisten und der SPD bekannt gewesen seien ${ }^{93}$.

Aber der Kanzler blieb weiterhin bei seiner Behauptung: Die SPD habe sich hinter seinem Rücken und ohne Absprache mit der Union zu Gesprächen mit der KPI getroffen. Am Donnerstagabend, dem 4. April 1968, wurde im sogenannten Dienstagskreis die Sache zur Sprache gebracht. Dieses wöchentliche Treffen der wichtigsten Führer beider Koalitionsparteien hatte nach dem Kreßbronner Gespräch Ende August 1967 langsam dessen Funktion übernommen. Zunächst hatte man dort die Antwort auf den zweiten Stoph-Briefes beraten, die Kiesinger am 28. September 1967 abschickte. Vor allem aufgrund der Verhandlungen um den Stoph-Brief wurde das inoffizielle Gremium nun zum bestimmenden Koalitionsgespräch der Führer beider Parteien. Ständig gehörten dem Kreis neben Kiesinger von der CDU Carstens, Heck, Rasner, von der CSU Stücklen und Guttenberg sowie von der SPD Brandt, Franke, Wehner und Karl Wienand an. Aber die Zusammenkunft verlief diesmal anders als von Unionsseite erwartet. Der Koalitionspartner zeigte sich keineswegs zerknirscht und kleinlaut; insbesondere galt das für Wehner. Es war ganz allgemein eine Eigenheit Wehners, wenn er sich angegriffen fühlte: Er griff seinerseits an, um Attacken zuvorzukommen. Immer wenn Wehner in die Defensive gedrängt worden sei, habe sich sein „Kämpferherz" gezeigt, meinte Carstens später. So auch bei dieser Sitzung. Der stellvertretende SPD-Vorsitzende habe sich zur Verblüffung der Unionsmitglieder vehement darüber beschwert, daß der Geheimdienst seine Erkenntnisse nicht auch ihm vorgelegt habe ${ }^{94}$. Auch der Vorsitzende fühlte sich umgangen. Brandt klagte noch zwanzig Jahre später über diesen Akt parteipolitischer Einseitigkeit einer Regierungsinstitution. „Mich zu unterrichten oder meine Stellungnahme als Parteivorsitzender einzuholen, hielt niemand für notwendig oder zweckmäßig", schrieb er zornig 95 .

91 AdKASt, Kiesinger I - 226, D/IV.6, A 007, Rasner an Kiesinger vom 5.4.1968.

$92 \mathrm{Vgl}$. Brandt, Begegnungen, S. 290. Die konservative Presse warf zunächst Brandt vor, ein längeres Gespräch mit Longo geführt zu haben. Aber das traf offenbar nicht zu. Der Außenminister hatte nur einen Satz mit dem italienischen Parteiführer gewechselt, weil er schnell den Flughafen erreichen mußte. „Boshaft könnte man sagen: ich ließ Kiesinger mit Longo allein.“

${ }_{93}$ Vgl. Frankfurter Allgemeine Zeitung, 10.4.1968.

94 Carstens, Gespräch mit dem Verfasser, 29.11.1989, und Diehl, Gespräch mit dem Verfasser, 29.11.1989. Diehl erinnert sich, daß Wehner oft darüber klagte, bei der Zustellung von Briefen oder Memoranden, etwa aus Moskau oder Ost-Berlin, übergangen worden zu sein.

95 Brandt, Erinnerungen, S. 182. 
Die SPD fühlte sich unschuldig. Sie betrachtete die Kontaktaufnahme zur KPI als Parteiangelegenheit. Ihr Vorhaben dem Koalitionspartner mitzuteilen, hielt sie nicht für erforderlich96. Die Sozialdemokraten beharrten außerdem darauf, es hätten keine Geheimgespräche stattgefunden. Falls die Union Auskunft verlangt hätte, wäre sie informiert worden. Um diesen Standpunkt zu unterstreichen, händigte die SPD-Führung anschließend dem Kanzler das Protokoll der Münchner Sitzung aus"7. Damit hatten beide Seiten ihre Auffassungen dargelegt. Die Angelegenheit wurde fortan in den gemeinsamen Gremien nicht mehr zur Sprache gebracht. Wehner wußte, daß damit die Sache natürlich nicht bereinigt war. Um die Wogen etwas zu glätten und die Bedeutung herauszustreichen, die er nach wie vor dem Bündnis mit Kiesinger beimaß, erklärte er Kiesinger handschriftlich in einem Geburtstagsbrief zwei Tage später, am 6. April: „Erlauben Sie $\mathrm{mir}$, bitte, Ihnen heute auch ganz persönlich viele gute Wünsche auf Ihrem Weg ins neue Lebensjahr mitzugeben." Er wünsche Kiesinger die Kraft, das große Werk zu meistern, das der Kanzler begonnen habe; auch die Kraft, „die Liebe aufzubringen, die notwendig ist, weil dieses Werk mit Menschen geschaffen werden muß, die Schwächen haben oder in vielem anders denken“. „Seien Sie versichert, daß ich zu meinem Teil helfen will. Es kommt wohl sehr darauf an, daß der Kern nicht faul werde. An diesem Tag danke ich Ihnen dafür, daß Sie mir Gelegenheit gegeben haben, mit zu wirken und ein wenig mit zu raten." 98

Das war ein hochinteressantes Schreiben, weil es die Meinungsverschiedenheiten gar nicht zu überbrücken versuchte, sondern die Probleme deutlich beim Namen nannte. Wehner sprach vermutlich von sich selbst, wenn er dem Kanzler die Kraft wünschte, Verständnis für diejenigen Menschen aufzubringen, die "Schwächen haben oder in vielem anders denken “. Spielte der Minister hier auf die heimlichen Kontakte an, wenn er von "Schwächen" sprach, oder meinte er seinen ständigen Drang, mit den Kommunisten der DDR in einen Dialog einzutreten? Wehner war sich darüber im klaren, daß er und die anderen Sozialdemokraten "in vielem anders" dachten als der Kanzler und dessen Partei. Er beschrieb hier genau das Problem der Koalition: Kiesinger und er mußten in ihren eigenen Parteien und in der Öffentlichkeit die Verbindung immer wieder bekräftigen und das gemeinsame Bündnis zu erhalten suchen. Dieser Grundsatz galt selbst dann, wenn die beiden führenden Persönlichkeiten Meinungsverschiedenheiten trennten. Daß der „Kern nicht faul“ werde - darauf müßten beide achten, schrieb daher Wehner. Aber diese Mahnung richtete er vermutlich an sich selbst. Denn hatten nicht die Sozialdemokraten gerade den Koalitionsgeist verletzt? Hatte die Union nicht zu Recht angemahnt, daß die SPD-Führung den Rahmen der Gemeinsamkeiten übertreten hatte? Oder handelte es sich hier nicht doch um eine versteckte Kritik an Kiesinger, die darauf deutete, daß der Kanzler von seinem Minister unterrichtet worden war und jetzt so tat, als habe man ihn hintergangen?

Wie dem auch sei, Wehner war auf Versöhnung bedacht. Zusätzlich zu seinem Brief sandte der Minister eine Abschrift des Bundestagsprotokolls vom Vortage. Er hatte es

\footnotetext{
96 Vgl. Schmoeckel/Kaiser, Vergessene Regierung, S. 185 f. Die Union machte der SPD eher einen Verstoß gegen den ungeschriebenen Verhaltenskodex in einer Koalition zum Vorwurf.

${ }^{77} \mathrm{Vgl}$. Timmermann, Im Vorfeld, S. 397. Es habe nur ungenaue öffentliche Angaben der SPD gegeben, die allerdings besagten, daß sie die Union rechtzeitig (!) informiert habe. Das Münchner Gesprächsprotokoll sei dem Kanzler ohne geheimnisvolle Umstände von der SPD selbst überreicht worden - „ein Argument mehr übrigens gegen die These, die Verhandlungen seien hinter dem Rücken des Kanzlers geführt worden", meint Timmermann.

98 AdKASt, Kiesinger I - 226, D/IV.6, Wehner an Kiesinger vom 6.4.1968.
} 
Kiesinger handschriftlich gewidmet: „Dem Herrn Bundeskanzler Kurt Georg Kiesinger in respektvoller Zueignung. 6. IV. 1968. Herbert Wehner." Die Textstelle dokumentiert die Entschiedenheit, mit der er dem Versuch der Opposition entgegentreten war, die unterschiedlichen Auffassungen der beiden Regierungsparteien in der Ost- und Deutschlandpolitik herauszustreichen. Der FDP-Vorsitzende, faßte Wehner zusammen, habe vor dem Bundestag erklärt, in der Öffentlichkeit sei immer noch der polemische Streit darüber im Gange, ob denn nun die Politik, die von dieser Regierung vertreten werde, die „bewährte alte" oder eine „dynamisch neue" Politik sei. Beim zweiten Teil seiner Frage habe der Herr Kollege Scheel betont, jetzt schaue er hinüber zur SPD-Fraktion ${ }^{99}$. Aber die Antwort auf die Frage, eine ganz rhetorische Frage, wie Wehner anmerkte, die hier in bezug auf die Politik gestellt worden sei, könne gar nicht sensationell sein. „In bezug auf die Deutschlandpolitik ist es die Politik, die das Kräfteverhältnis möglich macht", betonte Wehner vor den Abgeordneten, „angesichts einer Lage, die nur sehr gradweise mit unseren eigenen Kräften verändert werden kann. Wer darüber hinwegreden möchte, der täuscht sich gewaltig über die Härte des Geländes, auf dem, in dem und durch das hindurch diese Politik gemacht werden muß." 100

Indem Wehner die Große Koalition gegen Versuche des FDP-Vorsitzenden verteidigte, sie in der Außenpolitik auseinanderzudividieren, bewies er seine ungebrochene Treue zum Bündnis mit Kiesinger. Aber Wehner wäre nicht Wehner gewesen, wenn er das Bekenntnis nicht auf seine Weise abgelegt hätte! Er widersprach nicht ausdrücklich der Behauptung von unterschiedlichen Standpunkten, sondern erklärte lediglich, das Gelände sei „unwegsam“. Dennoch - für Kiesinger sollten die Worte bedeuten, in der Deutschlandpolitik zögen beide nach wie vor an einem Strang. Das stimmte aber so nicht mehr. Bisher hatte sich der Kanzler immer bereit gefunden, den Initiativen seines Ministers nachzugeben. Um des Koalitionsfriedens willen hatte er auch da eine Politik mitgetragen, wo ihm selbst $Z$ weifel über den Sinn eines Unternehmens gekommen waren. Die beiden Briefe an Stoph zählten dazu. Jetzt, nach der Aufdeckung der KPI-Kontakte und der deutlichen Distanzierung vom Bündnispartner, zeigte der Regierungschef nicht mehr die gleiche Bereitschaft, die SPD gewähren zu lassen. Mehr und mehr verfolgte er seine politische Leitlinie, die Annäherung an Moskau - unabhängig von Brandts Bemühungen, aber nicht um jeden Preis. Kiesinger kritisierte die DDR nun unbefangener als entspannungsfeindlich, und sie machte es ihm leicht: Anstatt die Bundesregierung beim Wort zu nehmen und Verhandlungen über die am 12. April 1967 vorgeschlagenen Themen einzuleiten, provozierte sie im Frühjahr 1968 eine dritte Krise um Berlin, die sogenannte „kleine Berlin-Krise“.

99 VdDB, 5. Wahlperiode, 168. Sitzung vom 5.4.1968, S. 8955.

100 AdKASt, Kiesinger I - 226, D/IV.6, Anlage zu Wehner an Kiesinger vom 6.4.1968. 